Addressing the collective action problem in multiple-purchaser PES: An experimental investigation of negotiated payment contributions 


\begin{abstract}
Involving multiple-purchasers in a PES scheme has the potential to deliver numerous benefits including cost-sharing, expanded financing and broadened scope. That few such schemes exist is evidence of a classic market failure resulting from incentives to free-ride on the payments of other purchasers. In the context of an experimental investigation, this paper explores the role of negotiation and binding pre-commitments to payments in solving that collective action problem. Our novel experimental setup involves two purchasers seeking a level of payment acceptable to a single provider while also agreeing their own individual contributions to that payment. Contrasting treatments are used to explore complexities of the conditions under which negotiations might take place including asymmetries between the purchasers, treatments with incomplete information and treatments with uncertainty over the levels of benefit. We find that those complexities change the ease with which a negotiated agreement is achieved as well as the relative size of the payoffs enjoyed by the different parties to the negotiations Our findings are generally positive, showing that under many circumstances parties to a multiple-purchaser PES can successfully negotiate a mutually agreeable schedule of payments and contributions.
\end{abstract}

\title{
Keywords
}

Payments for Ecosystem Services; Multiple Purchasers; Negotiation; Laboratory Experiment; Asymmetric and Uncertain payoffs.

\section{JEL classifications:}

C72; C92; D82; Q18; Q57 


\section{Introduction}

It is generally accepted that most environmental problems can be characterised as externalities arising from the public good nature of many environmental goods. Recognising this problem, the motivation for Payment for Ecosystem Service (PES) schemes is simple: internalise the externality. In other words, offer direct payments to ecosystem service (ES) providers in return for actions that deliver improved ES flows. While the particular term 'PES' is relatively newly coined (Gomez-Baggethun et al., 2010), the idea of paying providers dates back at least as far as Coase (1960). As recognised by Coase (1960) and many others since (e.g. Varian (1994), however, a mechanism for paying providers may only be part of the solution. In particular, if the ESs delivered by the PES scheme have public good properties and are enjoyed by multiple beneficiaries then a second problem arises; how to convince those beneficiaries to contribute to payments through the PES scheme when each has incentives to free ride. While much of the PES literature concentrates on the efficient incentivisation of providers on the supply-side of the PES market, this paper focuses on the demand-side obstacle brought about by the collective action problem.

Recent years have witnessed a rapid increase in the number of PES schemes instituted around the world (Schomers and Matzdorf, 2013). With regards to demand-side characteristics, these have tended to take one of two forms. At one extreme are those schemes delivering a flow of ESs that benefits a broad population. Not surprisingly, such PES schemes are not selforganising. The public good nature of the ES precipitates a classic prisoners' dilemma that mitigates against collective action. PES schemes develop in these circumstances only when public bodies, or occasionally NGOs, step in to ensure delivery on behalf of the constituency of beneficiaries that they represent. Examples of publically-funded PES schemes include the UK's Countryside Stewardship agri-environment programme which pays farmers to adopt wildlife-friendly land management practices, Australia's Bushtender Scheme (Stoneham et al., 
2003) which supports landowners in protecting native vegetation and New York City's investments in protecting the quality of its drinking water supply through payments to farmers in the Catskills/Delaware watershed (Smith and Porter, 2010).

At the other extreme, there are also numerous examples of PES schemes instituted by a single private organisation seeking a cost-effective mechanism to manage and/or protect a natural resource critical to their business activities. Examples of this kind include Nestle Water's payments to farmers to eliminate Nitrate pollution from the source of their Vittel mineral water product (Perrot-Maitre, 2006) and the scheme run by the Indonesian PLTA power company which pays upstream communities to moderate deforestation activities in order to reduce sedimentation in their hydropower dam (Fauzi and Anna, 2013).

One feature of all these schemes is that they are monopsonies; the PES market is created and funded through the patronage of a single purchaser. Far less common are schemes that channel payments from two or more beneficiaries. The advantages of such multiple-purchaser PES schemes are numerous. Most directly, by drawing in multiple sources of funding they offer the possibility of cost-sharing, thereby reducing the burden on any single purchaser and increasing the likelihood of institutional commitment to a PES scheme. Similarly, increased financing might allow for expansion of the scheme such that it delivers more substantial changes in natural resource management and enhances the benefit flows to each purchaser. Also, multiplepurchaser schemes might broaden the range of PES-funded investments ensuring that the natural resource management changes financed through the scheme are not unduly focused on delivery of a single ES outcome. Indeed, multiple purchaser schemes open up the possibility of co-ordinating the spatial targeting of payments in order to ensure an efficient delivery of multiple ES flows that advantage all beneficiaries (Smith and Day, 2014).

Given these benefits there has been increasing interest, particularly from the public sector, in the possibility of leveraging finance from multiple beneficiaries in PES schemes (Deal et al., 
2012; Defra, 2013; LaRocco and Deal, 2011). The UK government, for example, state that " $[\mathrm{t}]$ here is a need to explore new means to aggregate demand from beneficiaries and mobilise funding solutions", and that such approaches would "draw in multiple sources of funding and strengthen the overall economic case for action" (Defra, 2013, p23).

Of course, a central problem for multiple purchaser schemes is the collective action problem brought about by the public good nature of the ES services delivered by PES-funded interventions. As we show in the appendix (in the context of a stylised two-purchaser model), beneficiaries from a PES scheme will always have incentives to free ride when the possibility exists for some alternative beneficiary to foot the bill. Without further structure to the institutional arrangements, we would expect only the purchaser who stands to gain the most from the scheme to contribute to PES-funded investments.

Given the incentives of the multiple-purchaser problem it is perhaps surprising that some such schemes exist. One example, ${ }^{1}$ in the Los Negros watershed of Bolivia makes payments to farmers to protect threatened cloud forest with those payments being funded by an international biodiversity conservation donor and downstream irrigators wishing to stabilise dry-season water flows (Asquith et al., 2008). Importantly, the scheme arose through the mediation of an NGO (Fundación Natura Bolivia) who facilitated negotiations between providers and purchasers and established agreements between the parties regarding their commitments to the scheme. The key lesson of the Los Negros example is that the collective action problem can be overcome when parties make binding pre-commitments to contributions arrived at through a process of negotiation. While little studied in the PES literature, the role of negotiation in over-

\footnotetext{
${ }^{1}$ A second example, is provided by the Costa Rican PSA (Pagos por Servicios Ambientales) scheme. Operating since 1997, this programme draws in funding for forest protection and re-forestation from numerous national and international sources including hydroelectric companies, carbon markets, NGOs, a brewery and the tourism industry. Like the Bolivian example, these diverse purchasers commit to contributions which are collected by a single agency, the National Forest Finance Fund, who then acts as a single purchaser in the PES scheme.
} 
coming the collective action problem is at the heart of research examining that other great environmental public good provision problem; greenhouse gas emissions and climate change (Barrett, 1994; Nordhaus, 2015).

The core contribution of this paper is to explore the possibilities for multiple-purchaser PES with binding pre-commitments to payments; payments agreed through a process of multi-lateral negotiation. Section 2 explores previous research on negotiated agreements focusing on the experimental literature in this field. Indeed, our empirical contribution takes the form of an experimental investigation of negotiated agreements in a multiple purchaser PES. The details of that experimental design are outlined in Section 3. Our experiment contrasts numerous treatments designed to explore complexities of the conditions under which negotiations might take place that we expect typify potential multiple-purchaser PES schemes. In particular, we have treatments in which there are asymmetries between the purchasers, treatments with incomplete information and treatments with uncertainty. We review previous research relevant to those complexities in Section 2 and present the findings from our own experiment in Section 4. Our findings are generally positive, showing that under many circumstances parties to a multiple-purchaser PES can successfully negotiate a schedule of payments and contributions that work to the benefit of all. We show how those outcomes differ under different conditions and in Section 5 present our conclusions as to what our experimental findings tell us regarding how negotiations in multiple-purchaser PES schemes might be structured to effect efficient outcomes.

\section{Experimental Investigations of PES Markets and Negotiation}

Experimental methods have seen extensive use in the academic literature to examine various elements of PES mechanism design. In the main, those efforts have focused on monopsonistic PES. In that context, the key questions that have engaged the research community have concerned how to target payments at those providers that can deliver the greatest ES flow 
(Banerjee et al., 2014; Banerjee et al., 2012; Parkhurst and Shogren, 2007) and how the purchaser can exploit their monopsony power in order to enhance the cost-efficiency of the scheme (Krawczyk et al., 2016; Reeson et al., 2011).

Rather than the payment mechanism problem of PES design, our paper focuses on the collective action problem and particularly its solution through a process of negotiation. In that respect, our research builds on a long tradition of experimental investigation of bargaining in the wider economics literature (Camerer, 2003; Roth, 1995). In brief, research on bargaining has pursued two different paradigms; non-cooperative game theory and cooperative game theory. Noncooperative game theory focuses on the question of identifying the equilibrium outcomes that might arise from some defined procedure for bargaining between multiple strategic agents (Sutton, 1986). Cooperative game theory puts no structure on the bargaining procedure and instead focuses on the characteristics of different outcomes of negotiations; which groups of agents will cohere to coordinate their actions, what actions will groups agree to and how much will each benefit from that negotiated outcome (Osborne and Rubinstein, 1994).

In the ES literature experimental studies that specifically focus on the negotiation procedure are limited in number. Two studies by Bruce and Clark (Bruce and Clark, 2010a, b) consider bargaining between two stakeholders using an axiomatic, cooperative bargaining approach, where bargaining happens in continuous time. The same authors (Bruce and Clark (2012) expand on that work to include incomplete information treatments. Our research adopts the alternative paradigm, exploring bargaining in PES schemes through the lens of non-cooperative game theory. In particular, our experimental design presents a framework within which parties iterate through rounds of offer and counter-offer in seeking a negotiated agreement.

To retain simplicity and hence clarity, our experiments involve just three parties to those negotiations: two purchasers and one provider. By including a provider in the negotiations, purchasers not only have to negotiate their levels of contribution but they must also ensure that 
that the resulting offer is satisfactory for the provider. As per the power relationships we suspect typify most PES schemes, the provider is a price taker, able to accept or reject the payment offered by the purchasers, but not to independently propose an alternative payment level. That set-up contrasts with the traditional bargaining literature where pair-wise or multilateral bargaining commonly involves the division of a 'pie' between the players negotiating. Indeed, as far as the authors are aware, the set-up we develop to investigate multiple-purchaser PES has not been examined before in the experimental literature ${ }^{2}$.

We use this experimental framework to investigate three complexities that might typically characterise multiple-purchaser PES negotiations and examine how those complexities impact both on the likelihood of achieving a negotiated solution and on the levels and division of payments between the different negotiating parties.

First, a ubiquitous feature of potential multiple-purchaser PES is asymmetry in the purchasers. One dimension of possible asymmetry concerns differences in the degree to which purchasers stand to benefit from the ESs delivered by the PES. For example, in a PES scheme funding farm investments to improve water quality in the catchment of the River Fowey in south west England, the benefits to the water supply company who funded the scheme far outweighed those of other possible contributors including a downstream shellfish industry and a harbour authority contending with siltation issues from agricultural runoff (Day and Couldrick, 2013). In our experiment we capture such asymmetry by introducing differences in the gains realisable by purchasers from a deal being struck with the provider; what we refer to subsequently as gains inside the deal. A second dimension of asymmetry concerns differences in the overall financial means of purchasers. As an example, consider the Costa Rican PSA scheme (see footnote 1),

\footnotetext{
${ }^{2}$ Perhaps the closest parallel is provided by the experimental bargaining literature focused on land acquisition and development and the problem of sellers holding out for a higher (Cadigan et al., 2009; Shupp et al., 2013), however, this relates to negotiations that draw in all sellers so that land development can go ahead.
} 
where state funding derived from a gasoline tax dwarfs the resources available to large hydroelectric companies also contributing to the scheme. Interestingly, smaller hydroelectric companies with even smaller financial means do not contribute (Blackman and Woodward, 2010), In our experiment we capture such asymmetry between purchasers through introducing differences in the payoff purchasers receive if there is no deal; what we refer to subsequently as gains outside the deal.

Such disparities in the rewards both inside and outside of a deal have been examined previously in the context of bilateral negotiation (Camerer, 2003; Roth, 1995; Zwick and Mak, 2012) where experimental observations are often seen to deviate from game theoretical predictions. Zwick and Mak (2012) characterise behaviours into 'gaming' tendencies and 'fairness' tendencies with the former often the position taken by an advantaged negotiator and the latter by a disadvantaged negotiator. Moreover, Zwick and Mak (2012) propose that demand for fairness is subject to some form of cost-benefit evaluation. With asymmetric negotiators, the degree to which advantaged negotiators attempt to exploit their advantage depends on the cost they incur in doing so. Likewise, the degree to which disadvantaged negotiators attempt to achieve fairness depends on their cost in making such demands (Zwick and Chen, 1999).

A second area of complexity we explore concerns incomplete information, in particular whether the outcomes of multiple-purchaser PES negotiations change when knowledge of gains inside a deal and payoffs outside a deal are private information. It seems likely that in the context of a multiple-purchaser PES, negotiators will be unwilling to reveal such information either for reasons of commercial sensitivity or because that information may provide a strategic advantage to the other negotiator (Murnighan et al., 1999; Thompson and Hastie, 1990). It has been shown that asymmetries in information fundamentally changes the negotiation dynamic. With incomplete information, players can act strategically in an attempt to gain advantage; for example, rejecting a favourable offer in order to signal high patience, a strong bargaining 
position or a large outside option (Kennan and Wilson, 1993). In addition to theoretical work (Ausubel et al., 2002) there is a large literature on experimental studies of incomplete information (Camerer, 2003; Roth, 1995). The general conclusion from incomplete information laboratory experiments in bilateral bargaining games is that offers tend to be relatively lower and that responders accept those lower offers (Croson et al., 2003; Guth et al., 1996; Rapoport et al., 1996; Schmitt, 2004). Shupp et al. (2013) explore the effect of incomplete information on multilateral bargaining outcomes. They find that incomplete information increases bargaining delay and the likelihood of failed agreements. If this is a general result for multilateral bargaining then it may prove a significant barrier to achieving successful multiplepurchaser PES schemes.

A final area of complexity addressed in our work concerns how uncertainty over gains impacts on the outcome of negotiations. The stochastic natural processes through which ES flows are realised introduces significant uncertainty when purchasers are negotiating PES schemes. In the Los Negros PES in Bolivia, for example, Asquith et al. (2008) observe that one of the key obstacles to securing contributions from downstream farmers was a lack of certainty over the service benefits they would enjoy. While some experimental bargaining studies have introduced uncertainty into the players' payoffs (Pillutla and Murnighan, 1996; Roth and Malouf, 1979; Roth and Murnighan, 1982) most of these are designed to induce risk neutrality in participants. Additionally, there is some evidence that stochasticity affects cooperation in public goods games (Berger and Hershey, 1994; Dickinson, 1998; Keser and Montmarquette, 2008) with lower contributions from participants when payoffs are stochastic compared to when payoffs are deterministic. Overall, the lack of existing evidence makes predictions about the effect of uncertain gains from PES schemes difficult and this article is therefore an important contribution to that gap in knowledge.

\section{Methods}


In our experiment, three players are randomly assigned to a group. Two of the players assume the role of purchasers of ES, with the third player as the provider of the ES ${ }^{3}$. Neutral labels were used in the experiment, so that subjects were labelled player's 1, 2 and 3; nevertheless, for the remainder of this paper we shall refer to the two purchasers as Purchaser 1 and Purchaser 2 and the provider as the Provider to denote we are referring to the participants roles in the experimental setup.

\subsection{Payments}

Both purchasers and the provider began the experiment entitled to some default payment. Each participant was informed that they could forego their default payment in favour of a deal payment, but only if all three members of the group agreed to that arrangement. For the two purchasers, their deal payment exceeded their default payment such that they were always incentivised to reach a deal. In contrast, for the provider their deal payment was always zero.

To persuade the provider to incur the cost of forgoing their default payment, the two purchasers were given the opportunity to team-up and offer the provider a payment. The essential challenge of the experiment was for the purchasers to agree how much each should contribute to an offer that was sufficiently generous to persuade the provider to agree to the deal. Obviously, the most it would ever make sense for one purchaser to contribute to such a payment is the difference between their deal payment and their default payment. Though for each purchaser, the incentive is to contribute as little as possible hoping that the other purchaser will commit sufficient funds to the offer to ensure that the provider also agrees to the deal.

\subsection{Negotiation procedure}

\footnotetext{
${ }^{3}$ Experiment participants did not know the identities of the other members of their group and the members of each group changed from task to task.
} 
In naturally occurring bargaining, players often alternate between offers and counter-offers, a structure mimicked by our experiment. Accordingly, bargaining began with purchaser 1 submitting a proposal to purchaser 2. purchaser 1's proposal suggests an amount that the two purchasers should offer to the provider, detailing the contribution that they themselves are willing to make and the contribution expected from purchaser 2. If purchaser 2 agreed to that proposal, then the offer was sent to the provider for consideration. If the provider also agreed then negotiations are over and a deal is done. Alternatively, if the proposal or offer was rejected then a second round of bargaining was initiated. In this second round, purchaser 2 had the opportunity to make a counterproposal. If this counterproposal was agreed by both purchaser 1 and the provider then a deal was done; otherwise the process of proposal and counterproposal continued until all players agree or until negotiations fail. Figure 1 details the negotiation procedure.

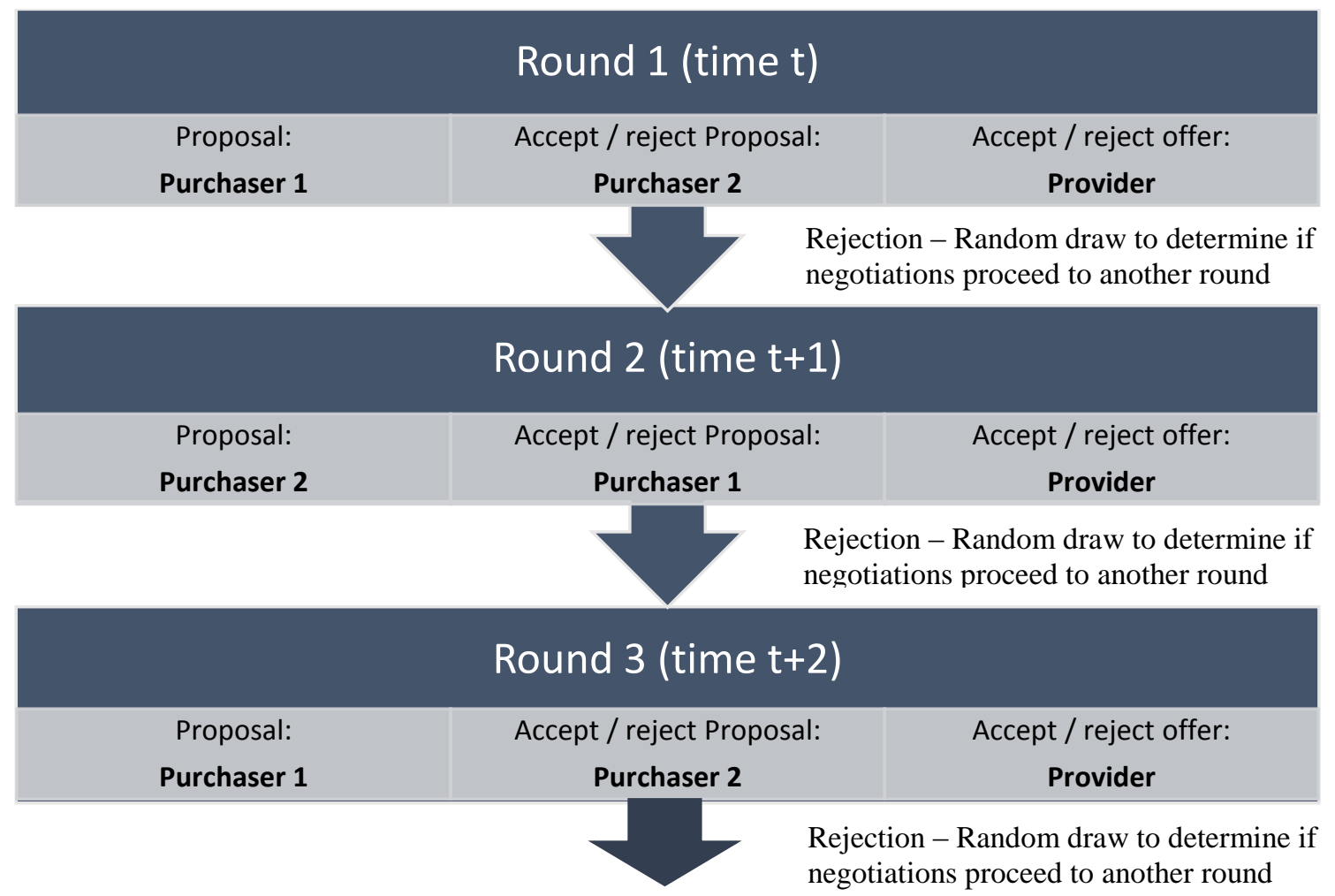

Figure 1. The negotiation procedure used in all experiment treatments. 
All decisions, proposals and acceptances, were subject to time limits. Those time limits varied depending on the treatment, subjects had 50 seconds to make the first proposal and 30 seconds for each subsequent proposal in the uncertainty treatment and 35 seconds for the first proposal and 20 seconds for each subsequent proposal in all other treatments. In the event that a purchaser timed out when making a proposal default contributions of $£ 0$ for each purchaser were submitted; when a responder (purchaser or provider) timed out the default submission was rejection.

Negotiations proceeded through a maximum of 15 rounds. To represent the cost of negotiating, rejecting a proposal and therefore blocking a deal came with an exogenous risk of the negotiations failing ${ }^{4}$. That risk was randomly realised by the computer each time a rejection was made, with odds of failure being clearly displayed to the subjects as in Figure 2. Those odds of failure increased as the rounds of negotiation progressed putting increasing pressure on the subjects to reach a deal. The experimental walkthrough provided to participants can be found in Appendix A to this paper.

\footnotetext{
${ }^{4}$ An example of an exogenous risk to negotiations can be seen in (Muthoo, 2002) who propose that while two firms negotiate over how to divide the profit from the exploitation of a particularly technology a third firm invents a new technology that makes their existing technology obsolete.
} 




Figure 2. Experiment screenshot

\subsection{Performance measures}

Five key measures are used to assess the experimental results. The first two measures, success and ease of a deal, measure if a deal was reached and the ease of the negotiation process. The first measure, success of the negotiation, measures the proportion of deals with agreement reached between all parties. The second measure, ease of reaching a deal, measures the rounds of negotiation to reach a successful deal. Three further measures assess the composition of payoffs and contributions making up a deal. The third measure, contribution, measures the payment made by an individual purchaser to the provider, with the division of contribution equal to each purchaser's share of the payment. The fourth measure uses the concept of a surplus, here we define the surplus as the sum of the difference between the deal payments and the default payments, in other words, the surplus is the aggregate gains from a deal; with the 
division of surplus equal to the share of surplus for each party. The fifth measure, the level of payoffs, measures the final payoffs received by each party.

\subsection{Experimental treatments}

We use our experimental design to investigate a number of complexities that might typically arise in negotiation and examine how those complexities impact both on the likelihood of achieving a negotiated solution to the problem of splitting payment contributions and on the levels and division of payments between the different negotiating parties. The complexities we focus on concern asymmetries in the purchasing parties, incomplete information and uncertainty. The treatments (described subsequently) are summarised in the first few columns of Table 1 .

\subsection{Asymmetry in the purchasers}

Symmetry - Treatments $1 A$ and $1 B$

Two treatments are included with symmetric default and deal payments for the purchasers. In Treatment $1 \mathrm{~A}$, the purchasers have deal payments of $£ 15$ and all parties have default payments of $£ 7.50$. From the point of view of each purchaser, therefore, it is just cost effective to make a bilateral deal with the provider. Under these circumstances do the purchasers split the contributions equally? Do they offer just enough to keep the provider interested, or are they forced to give up some of the surplus to the provider? Ultimatum experiments show that responders are able to get more than the game theoretical prediction of close to zero but generally less than an equal split and evidence from (Schmitt, 2004) on alternating bargaining suggests that players adjust their offers until they find a minimum acceptable offer.

In Treatment 1B the size of the surplus is increased (purchasers deal payments equal $£ 20$ ). We are interested in changes to the agreements as the benefits from making a deal increased. Are deals reached more easily and does the provider hold out for a higher payment? 
Treatment 2 introduces asymmetry in deal payments. In Treatment 2A, the deal payments are $£ 18$ for purchaser 1 and $£ 12$ for purchaser 2 with default payments of $£ 7.50$ for all three players. Accordingly, it is possible for purchaser 1 to form a cost-effective bilateral deal with the provider but not purchaser 2. Observe that the deal payments in this Treatment give the same overall surplus from a deal as Treatment 1A (sum of deal $£ 30$ minus sum of default $£ 22.50$ gives $£ 7.50$ surplus).

By including asymmetry in the benefits of a deal we wished to explore whether the purchasers' contributions differ. A number of experiments—notably, (Bruce and Clark, 2010a, b; Hoffman and Spitzer, 1985; Roth et al., 1981) — found that their subjects were drawn towards Paretoefficient outcomes that equalized payoffs. In order to achieve equal payoffs within our multilateral multiple-purchaser setup the purchasers would need to agree to an unequal division of contributions. This treatment provides insights into whether the subjects are motivated by equality of contribution over equal payoffs.

Asymmetry in the income of the purchasers (Treatments 3A)

While purchasers may not differ in terms of the additional benefits they stand to realise from a deal, they may differ in terms of the overall level of benefits they enjoy. In Treatment 3A deal payments are $£ 18$ for Purchaser 1 and $£ 12$ for Purchaser 2, while their corresponding default payments were $£ 10.50$ and $£ 4.50$. As such, both purchasers stood to make the same gain of $£ 7.50$ from a deal. Observe again that the total surplus is comparable to previous Treatments $1 \mathrm{~A}$ and $2 \mathrm{~A}$.

Two differences are important in Treatment 3A. Firstly, equalising all players payoffs cannot be achieved without purchaser 1 accepting a deal payment less than her default payment. Secondly, the setup means that the purchasers cannot simultaneously reach a deal with an equal 
division of surplus and equal payoffs. This treatment provides insights into whether purchasers are motivated by equality in surplus over equality in payoffs.

\subsection{Incomplete information}

Treatments $2 B, 2 C, 3 B$ and $3 C$

In both Treatments $2 \mathrm{~B}$ and $2 \mathrm{C}$ the deal and default payments are identical to Treatment $2 \mathrm{~A}$; two additional treatments, $3 \mathrm{~B}$ and $3 \mathrm{C}$ are analogous to Treatments $2 \mathrm{~B}$ and $2 \mathrm{C}$ but with the deal and default payments of Treatment 3A.

In the real world, it is unlikely that purchasers, negotiating over contributions, will reveal the level of benefits they stand to enjoy from a deal being done. To reflect that reality, the deal payments in Treatments $2 \mathrm{~B}$ and $3 \mathrm{~B}$ were private information; only a Purchaser knew what they stood to gain from a deal, in addition, Treatments $2 \mathrm{C}$ and $3 \mathrm{C}$ introduce completely private information, with each player only knowing their own deal and default payments. Shupp et al. (2013) explore incomplete information and find that negotiation takes longer and are more likely to result in failure. Contrary evidence shows that acceptance rates are higher with incomplete information perhaps because envy of the other player's payoff is removed with players instead focusing on their monetary payoff rather than relative payoff (Bolton and Ockenfels, 2000; Schmitt, 2004). Our experimental design allows the ease of reaching a deal to be measured through the number of rounds of negotiation.

In the incomplete information treatments the subjects are unable to focus on equalisation of payoffs or the division of surplus because they no longer have all the required information. We are therefore interested in changes to the division of surplus between the parties, for example, do the purchasers move to equalise contributions and is the provider able to extract any of the surplus? Furthermore, we explore if subjects are undertaking some form of cost benefit analysis as suggested by Zwick and Chen (1999) and Zwick and Mak (2012). Under this hypothesis, we would expect that in Treatment 2, as purchaser 1 has more to gain from a deal, and therefore 
also more to lose from not reaching a deal, that purchaser 1's contributes more to the payment compared to Treatment 3.

\subsection{Uncertainty}

Treatments $4+$ and 4 -

Treatments 4+ and 4- explored uncertain outcomes. In those treatments, participants are faced by an uncertain future characterised by two possible states of the world, $a$ and $b$, each of which has a 0.5 probability of becoming reality. The deal payments enjoyed by purchasers in these two states of the world are different. Accordingly, our experiment allows purchasers to make conditional offers; that is to say, purchasers decide how much they are going to contribute to a payment in each 'state of the world'. The provider therefore receives two offers; one detailing how much they will be paid in 'state of the world $a$ ' and another for 'state of the world $b$ '. During negotiations all parties could signal regarding which, if either, of the payments in the two 'states of the world' had caused them to reject a proposal or offer.

Of primary interest was to see if uncertainty alter the success and ease of reaching deal as well as any differences in the composition of payments and contributions in different states of the world. Do the purchasers share the risk of the uncertain benefit between each other and is any of that risk transferred onto the provider.

\subsection{Implementation}

The experiment was conducted in the Centre for Behavioural and Experimental Social Sciences at the University of East Anglia (UEA). In total, 204 subjects participated in 14 sessions with between 12 and 18 subjects in each session. Subjects were recruited from undergraduate and graduate populations from all disciplines using the online recruitment system (ORSEE) (Greiner, 2004). No subject participated in more than one session, but each subject participated in multiple treatments within a single session. Before each treatment the subjects were assigned 
a new role (Purchaser 1, 2 or Provider) and matched with a new group. The experiment was programmed and conducted in the z-Tree software (Fischbacher, 2007).

The same procedure was followed in each session. All students were seated at a private computer terminal with no communication allowed. Instructions were read aloud and included a detailed walkthrough in which subjects could see how the tasks would progress from the perspective of all the different roles. Any questions were answered in private. At the end of the experiment subjects completed a short questionnaire. The final payments were from one randomly selected round and an additional $£ 2.50$ participation fee. The sessions lasted approximately 1 hour and 30 minutes.

\section{Results}

\subsection{Irrational responses}

In total 412 deals were completed. If we take the standpoint that it would be irrational for participants to accept a deal which would make them worse off than their default payment; then, of the 412 deals, 47 deals can be classified as irrational for at least one of the participants, leaving 365 rational deals. One can hypothesise about the reason for these irrational deals; for example, although great care was taken to explain the procedure, the tasks required reasonable levels of engagement that may not been committed by all participants. In addition, the role of the subject, deal and default payments changed from task to task. This complexity combined with the time pressure could go some way to explaining such behaviour. A small number of participants admitted to making a mistake due to the time pressure. It should also be noted that other reasons such as altruistic behaviour could potentially explain some of the deals we have 
classified as irrational. Unless otherwise stated we use only those deals which can be classified as rational for all players in the following analysis. ${ }^{5}$

Table 1 summarises the results for all treatments of the experiment and Table 2 summarises the division of contribution, division of surplus and division of payoffs for all deterministic treatment of the experiment.

\subsection{Symmetrical purchasers.}

In Treatment 1 the purchasers' deal and default payments are symmetric and all information is public. Treatment $1 \mathrm{~A}$ and $1 \mathrm{~B}$ differ only in the deal payments for the two purchasers; $£ 15$ in Treatment 1A compared to $£ 20$ in Treatment 1B.

Observe the deal success and average rounds to completion in Table 1 . The majority of negotiations result in deals being completed, 39 from 40 for both Treatment $1 \mathrm{~A}$ and 1B, and those deals were completed relatively quickly, averaging 3.3 rounds for Treatment $1 \mathrm{~A}$ and 3.0 rounds for Treatment 1B. In Table 1 the average payoffs for Treatment $1 \mathrm{~A}$ for purchaser 1 and purchaser 2 were $£ 10.22$ and $£ 10.18$ respectively, and the provider $£ 9.60$. In Treatment $1 \mathrm{~B}$ both purchasers received average payoffs of $£ 13.80$, and the provider $£ 12.40$. In both treatments the differences between the provider's and the purchasers' payoffs are statistically significant (Wilcoxon-Rank-Sum Treatment $1 p$-value $=0.000$, Treatment $2 p$-value $=0.000$ ).

While the offer and counter-offer negotiation between symmetrical purchasers tends to result in agreement over contributions that give them very similar payoffs, the provider, a passive actor in the negotiations, is prepared to settle for an amount somewhat smaller. This finding is consistent with previous experimental evidence (Roth, 1995; Schmitt, 2004) where passive negotiated are shown to negotiate towards a minimal acceptable amount.

\footnotetext{
${ }^{5}$ An equivalent analysis was conducted in which subjects who were involved in two or more irrational deals were classified as 'irrational subjects' and all groups that they were involved in were removed from the data. This resulted in a total of 349 deals. The results were qualitatively identical to the results presented here.
} 


\begin{tabular}{|c|c|c|c|c|c|c|c|c|c|c|c|c|c|c|c|}
\hline \multirow{2}{*}{\multicolumn{2}{|c|}{ Treatment }} & \multirow{2}{*}{ Information } & \multicolumn{3}{|c|}{ Default payment } & \multicolumn{3}{|c|}{ Deal payment } & \multirow{2}{*}{$\begin{array}{c}\text { Deal } \\
\text { Success }\end{array}$} & \multirow{2}{*}{$\begin{array}{c}\text { Average } \\
\text { Rounds to } \\
\text { completion }\end{array}$} & \multicolumn{2}{|c|}{$\begin{array}{c}\text { Average } \\
\text { Contribution }\end{array}$} & \multicolumn{3}{|c|}{ Average Payoff } \\
\hline & & & P1 & $\mathbf{P 2}$ & Provider & P1 & $\mathbf{P 2}$ & Provider & & & P1 & $\mathbf{P 2}$ & P1 & $\mathbf{P 2}$ & Provider \\
\hline \multirow[t]{2}{*}{1} & $\mathbf{A}$ & Full Public & $£ 7.50$ & $£ 7.50$ & $£ 7.50$ & $£ 15$ & $£ 15$ & $£ 0$ & $39 / 40$ & $\begin{array}{c}3.3 \\
(2.8)\end{array}$ & $\begin{array}{l}£ 4.78 \\
(0.83)\end{array}$ & $\begin{array}{l}£ 4.82 \\
(0.74)\end{array}$ & $\begin{array}{r}£ 10.22 \\
(0.83)\end{array}$ & $\begin{array}{l}£ 10.18 \\
(0.74)\end{array}$ & $\begin{array}{l}£ 9.60 \\
(1.49)\end{array}$ \\
\hline & $\mathbf{B}$ & Full Public & $£ 7.50$ & $£ 7.50$ & $£ 7.50$ & $£ 20$ & $£ 20$ & $£ 0$ & $39 / 40$ & $\begin{array}{c}3.0 \\
(2.3)\end{array}$ & $\begin{array}{l}£ 6.20 \\
(0.77)\end{array}$ & $\begin{array}{l}£ 6.20 \\
(0.87)\end{array}$ & $\begin{array}{c}£ 13.80 \\
(0.77)\end{array}$ & $\begin{array}{c}£ 13.80 \\
(0.87)\end{array}$ & $\begin{array}{c}£ 12.40 \\
(1.61)\end{array}$ \\
\hline \multirow[t]{3}{*}{2} & $\mathbf{A}$ & Full Public & $£ 7.50$ & $£ 7.50$ & $£ 7.50$ & $£ 18$ & $£ 12$ & $£ 0$ & $63 / 73$ & $\begin{array}{c}4.6 \\
(3.5)\end{array}$ & $\begin{array}{l}£ 7.55 \\
(0.91)\end{array}$ & $\begin{array}{l}£ 2.26 \\
(0.77)\end{array}$ & $\begin{array}{r}£ 10.45 \\
(0.91)\end{array}$ & $\begin{array}{l}£ 9.74 \\
(0.77)\end{array}$ & $\begin{array}{l}£ 9.81 \\
(0.78)\end{array}$ \\
\hline & $\mathbf{B}$ & Deal Private & $£ 7.50$ & $£ 7.50$ & $£ 7.50$ & $£ 18$ & $£ 12$ & $£ 0$ & $32 / 38$ & $\begin{array}{c}7.6 \\
(3.2)\end{array}$ & $\begin{array}{l}£ 5.89 \\
(1.21)\end{array}$ & $\begin{array}{l}£ 3.46 \\
(0.91)\end{array}$ & $\begin{array}{c}£ 12.11 \\
(1.21)\end{array}$ & $\begin{array}{l}£ 8.54 \\
(0.91)\end{array}$ & $\begin{array}{l}£ 9.35 \\
(0.70)\end{array}$ \\
\hline & $\mathbf{C}$ & $\begin{array}{c}\text { Deal \& Default } \\
\text { Private }\end{array}$ & $£ 7.50$ & $£ 7.50$ & $£ 7.50$ & $£ 18$ & $£ 12$ & $£ 0$ & $24 / 30$ & $\begin{array}{c}8.2 \\
(3.4)\end{array}$ & $\begin{array}{l}£ 5.70 \\
(1.42)\end{array}$ & $\begin{array}{l}£ 3.53 \\
(1.04)\end{array}$ & $\begin{array}{c}£ 12.30 \\
(1.42)\end{array}$ & $\begin{array}{l}£ 8.47 \\
(1.04)\end{array}$ & $\begin{array}{l}£ 9.23 \\
(0.92)\end{array}$ \\
\hline \multirow[t]{3}{*}{3} & $\mathbf{A}$ & Full Public & $£ 10.50$ & $£ 4.50$ & $£ 7.50$ & $£ 18$ & $£ 12$ & $£ 0$ & $36 / 40$ & $\begin{array}{c}6.5 \\
(3.7)\end{array}$ & $\begin{array}{l}£ 6.08 \\
(0.94)\end{array}$ & $\begin{array}{l}£ 3.36 \\
(1.13)\end{array}$ & $\begin{array}{c}£ 11.92 \\
(0.94)\end{array}$ & $\begin{array}{l}£ 8.64 \\
(1.13)\end{array}$ & $\begin{array}{l}£ 9.44 \\
(1.07)\end{array}$ \\
\hline & $\mathbf{B}$ & Deal Private & $£ 10.50$ & $£ 4.50$ & $£ 7.50$ & $£ 18$ & $£ 12$ & $£ 0$ & $32 / 41$ & $\begin{array}{c}7.4 \\
(3.1)\end{array}$ & $\begin{array}{l}£ 5.50 \\
(1.05)\end{array}$ & $\begin{array}{l}£ 3.81 \\
(0.81)\end{array}$ & $\begin{array}{c}£ 12.50 \\
(1.05)\end{array}$ & $\begin{array}{l}£ 8.19 \\
(0.81)\end{array}$ & $\begin{array}{l}£ 9.32 \\
(0.84)\end{array}$ \\
\hline & $\mathbf{C}$ & $\begin{array}{c}\text { Deal \& Default } \\
\text { Private }\end{array}$ & $£ 10.50$ & $£ 4.50$ & $£ 7.50$ & $£ 18$ & $£ 12$ & $£ 0$ & $35 / 40$ & $\begin{array}{c}6.2 \\
(3.7)\end{array}$ & $\begin{array}{l}£ 4.84 \\
(0.81)\end{array}$ & $\begin{array}{l}£ 4.40 \\
(0.83)\end{array}$ & $\begin{array}{c}£ 13.16 \\
(0.81)\end{array}$ & $\begin{array}{l}£ 7.60 \\
(0.83)\end{array}$ & $\begin{array}{l}£ 9.24 \\
(1.34)\end{array}$ \\
\hline \multirow{2}{*}{$4+$} & $\mathbf{a}$ & \multirow{2}{*}{ Full Public } & \multirow{2}{*}{$£ 7.50$} & \multirow{2}{*}{$£ 7.50$} & \multirow{2}{*}{$£ 7.50$} & $£ 21$ & $£ 15$ & & & 5.3 & $\begin{array}{l}£ 8.47 \\
(0.97)\end{array}$ & $\begin{array}{l}£ 2.59 \\
(1.28)\end{array}$ & $\begin{array}{c}£ 12.53 \\
(0.97)\end{array}$ & $\begin{array}{c}£ 12.41 \\
(1.28)\end{array}$ & $\begin{array}{l}£ 11.06 \\
(1.13)\end{array}$ \\
\hline & $\mathbf{b}$ & & & & & $£ 15$ & $£ 9$ & 20 & 34150 & (3.7) & $\begin{array}{l}£ 6.42 \\
(0.73)\end{array}$ & $\begin{array}{l}£ 1.75 \\
(1.36)\end{array}$ & $\begin{array}{l}£ 8.58 \\
(0.73)\end{array}$ & $\begin{array}{l}£ 7.25 \\
(1.36)\end{array}$ & $\begin{array}{l}£ 8.16 \\
(0.82)\end{array}$ \\
\hline \multirow{2}{*}{$4-$} & $\mathbf{a}$ & \multirow{2}{*}{ Full Public } & \multirow{2}{*}{$£ 7.50$} & \multirow{2}{*}{$£ 7.50$} & \multirow{2}{*}{$£ 7.50$} & $£ 21$ & $£ 9$ & & & 3.9 & $\begin{array}{l}£ 9.13 \\
(1.29)\end{array}$ & $\begin{array}{l}£ 0.57 \\
(0.72)\end{array}$ & $\begin{array}{r}£ 11.87 \\
(1.29)\end{array}$ & $\begin{array}{l}£ 8.43 \\
(0.72)\end{array}$ & $\begin{array}{l}£ 9.70 \\
(0.80)\end{array}$ \\
\hline & $\mathbf{b}$ & & & & & $£ 15$ & $£ 15$ & & & $(2.7)$ & $\begin{array}{l}£ 4.91 \\
(0.45)\end{array}$ & $\begin{array}{l}£ 4.81 \\
(0.52)\end{array}$ & $\begin{array}{c}£ 10.09 \\
(0.45)\end{array}$ & $\begin{array}{l}£ 10.19 \\
(0.52)\end{array}$ & $\begin{array}{l}£ 9.73 \\
(0.88)\end{array}$ \\
\hline
\end{tabular}

Table 1. Summary of results across all treatments. 
For treatment 4, + represents treatment with positive correlation between the purchasers deal payments and - represents the treatment with negative correlation. $a$ and $b$ represent the responses to 'state of the world $a$ ' and 'state of the world b' respectively. Averages are means with standard deviations in brackets.

\begin{tabular}{|c|c|c|c|c|c|c|c|c|c|c|c|c|c|}
\hline \multirow{2}{*}{\multicolumn{2}{|c|}{ Treatment }} & \multirow[b]{2}{*}{ Information } & \multicolumn{3}{|c|}{ Division of contribution \% } & \multicolumn{4}{|c|}{ Division of surplus \% } & \multicolumn{4}{|c|}{ Division of Total Payoffs \% } \\
\hline & & & $\begin{array}{c}\text { Total } \\
\text { Contribution } \\
\text { to Provider }\end{array}$ & P1 & $\mathbf{P 2}$ & $\begin{array}{c}\text { Total } \\
\text { surplus }\end{array}$ & P1 & $\mathbf{P 2}$ & Provider & $\begin{array}{c}\text { Total } \\
\text { payoff }\end{array}$ & P1 & $\mathbf{P 2}$ & Provider \\
\hline \multirow[t]{2}{*}{1} & $\mathbf{A}$ & Full/Public & $£ 9.60$ & $49.8 \%$ & $50.2 \%$ & $£ 7.50$ & $36.2 \%$ & $35.8 \%$ & $28.0 \%$ & $£ 30$ & $34.1 \%$ & $33.9 \%$ & $32.0 \%$ \\
\hline & B & Full/Public & $£ 12.40$ & $50.0 \%$ & $50.0 \%$ & $£ 17.50$ & $36.0 \%$ & $36.0 \%$ & $28.0 \%$ & $£ 40$ & $34.5 \%$ & $34.5 \%$ & $31.0 \%$ \\
\hline \multirow[t]{3}{*}{2} & $\mathbf{A}$ & Full/Public & $£ 9.81$ & $77.0 \%$ & $23.1 \%$ & $£ 7.50$ & $39.4 \%$ & $29.8 \%$ & $30.8 \%$ & $£ 30$ & $34.8 \%$ & $32.5 \%$ & $32.7 \%$ \\
\hline & B & Deal Private & $£ 9.35$ & $63.0 \%$ & $37.0 \%$ & $£ 7.50$ & $61.4 \%$ & $13.9 \%$ & $24.7 \%$ & $£ 30$ & $40.4 \%$ & $28.5 \%$ & $31.2 \%$ \\
\hline & $\mathbf{C}$ & $\begin{array}{l}\text { Deal \& } \\
\text { Default } \\
\text { Private }\end{array}$ & $£ 9.23$ & $61.7 \%$ & $38.3 \%$ & $£ 7.50$ & $64.0 \%$ & $12.9 \%$ & $23.1 \%$ & $£ 30$ & $41.0 \%$ & $28.2 \%$ & $30.8 \%$ \\
\hline \multirow[t]{3}{*}{3} & $\mathbf{A}$ & Full/Public & $£ 9.44$ & $64.4 \%$ & $35.6 \%$ & $£ 7.50$ & $19.0 \%$ & $55.2 \%$ & $25.9 \%$ & $£ 30$ & $39.8 \%$ & $28.8 \%$ & $31.5 \%$ \\
\hline & $\mathbf{B}$ & Deal Private & $£ 9.32$ & $59.1 \%$ & $40.9 \%$ & $£ 7.50$ & $26.6 \%$ & $49.2 \%$ & $24.2 \%$ & $£ 30$ & $41.7 \%$ & $27.3 \%$ & $31.1 \%$ \\
\hline & $\mathbf{C}$ & $\begin{array}{l}\text { Deal \& } \\
\text { Default } \\
\text { Private }\end{array}$ & $£ 9.24$ & $52.4 \%$ & $47.6 \%$ & $£ 7.50$ & $35.5 \%$ & $41.3 \%$ & $23.2 \%$ & $£ 30$ & $43.9 \%$ & $25.3 \%$ & $30.8 \%$ \\
\hline
\end{tabular}

Table 2. Summary of the division of contribution, division of surplus, and division of payoffs across all deterministic

\section{treatments.}




\subsection{Asymmetrical purchasers.}

Treatment 2 introduces asymmetry into the deal payments; specifically, purchaser 1 has a deal payment of $£ 18$ and purchaser 2 has a deal payment of $£ 12$.

In Treatment $2 \mathrm{~A}^{6}$ our first observation is that participants found it harder to complete a deal; the number of negotiation rounds averaged 4.6 (as compared to 3.3 in the Treatment $1 \mathrm{~A}$ and 3.0 in Treatment 1B). Figure 3 shows the distribution of negotiation rounds until deals were completed for symmetric deal treatments (1A and $1 \mathrm{~B})$ and asymmetric deal Treatments $(2 \mathrm{~A})$ a Wilcoxon-Rank-Sum test shows deals were completed quicker in the symmetric treatments ( $p$ value $=0.010)$

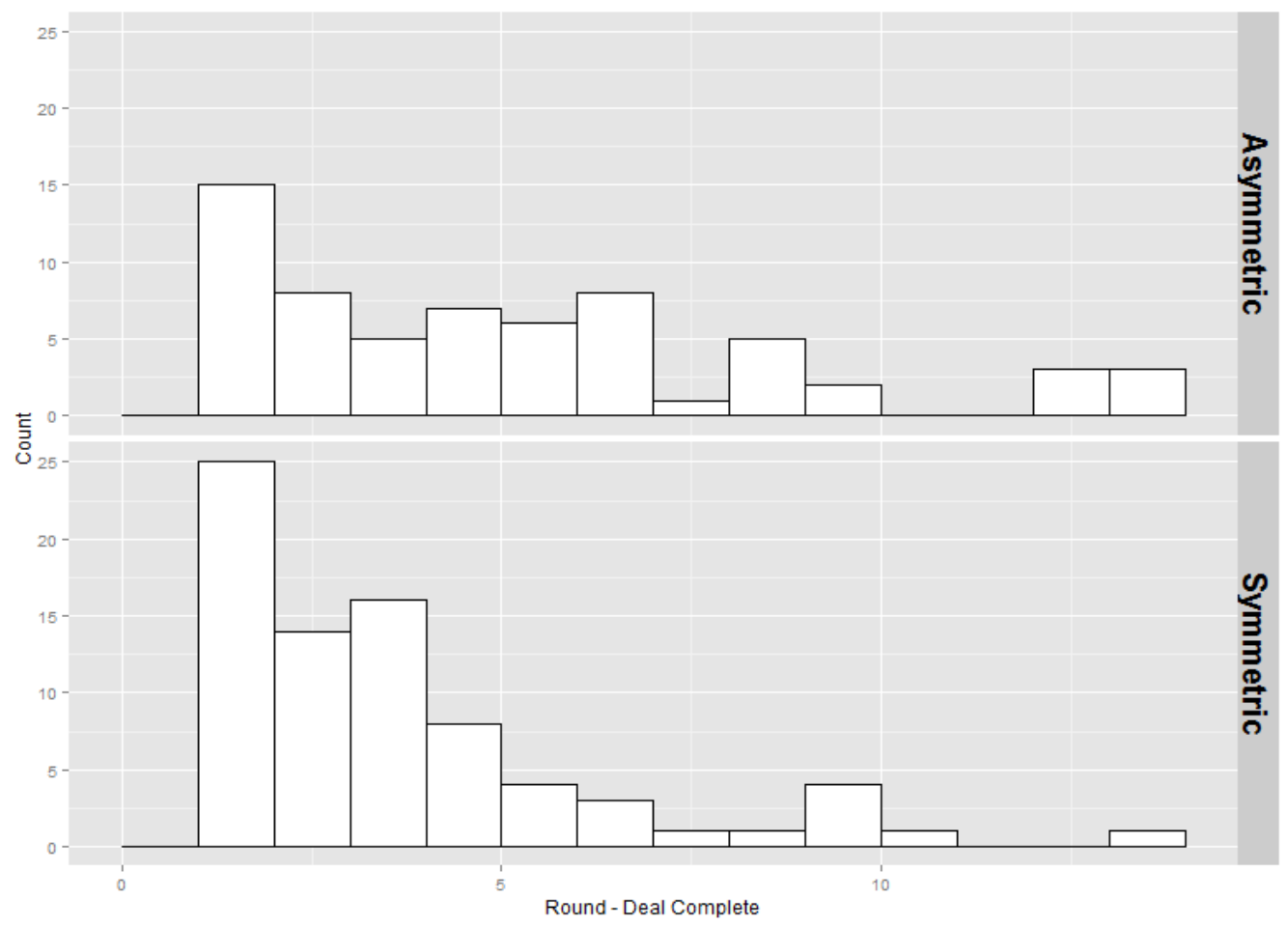

Figure 3. Number of rounds until deal completed for symmetric (1A 1B) and asymmetric (2A) experimental treatments.

\footnotetext{
${ }^{6}$ An additional treatment similar treatment to Treatment 2A was included with the deal payments of Purchaser 1 and Purchaser 2 swapped. Accordingly it was the subject with the lower, £12.00, deal payment who opened the negotiations. The results are qualitatively identical and are therefore reported grouped together with treatment 2A.
} 
With asymmetry in deal payments the subjects cannot achieve equality over all measures of outcome. If purchasers agree to equal contributions then purchaser 1will enjoy a larger payoff. If they agree to an equal payoff then purchaser 1 will have to make a larger contribution. In Treatment 2A we observe a statistically significant tendency towards the latter outcome; the average contribution of purchaser 1 is $£ 7.55$ and purchaser 2 is $£ 2.26$ (Wilcoxon-Rank-Sum, $p$-value $=0.000)$. Purchaser 1 therefore contributed more to the deal but on average still ended up with a significantly higher average payoff (£10.45) than both purchaser $2, £ 9.74$ (WilcoxonRank-Sum, $p$-value $=0.000)$ or the provider, $£ 9.81$ (Wilcoxon-Rank-Sum, $p$-value $=0.000)$. Since the purchasers have equal default payments, those differences in payoffs translates directly into statistically significance differences in the division of surplus.

Figure 4 plots the share of the surplus for deals agreed in the symmetric (1A) and asymmetric treatments (2A). It is constructed as a ternary plot with purchaser 1 on the left edge, purchaser 2 on the bottom edge and the provider on the right edge. Each edge measures the division of surplus as a proportion of the whole and as such spans the range from 0-1. Each point plotted in the diagram represents a completed deal and the mean division of surplus amounts (reported in Table 2) are plotted as solid lines. In the symmetric treatment both purchaser $1,36.2 \%$, and purchaser 2, 35.8\%, claim a significantly higher division of the surplus than the provider, $28.0 \%$ (Wilcoxon-Rank-Sum, $p$-value $=0.001$ and $p$-value $=0.001$ ). However, in the asymmetric treatment purchaser $1(39.4 \%)$ claims statistically significant higher division of the surplus than either purchaser $2(29.8 \%)$ or the provider (30.8\%) (Wilcoxon-Rank-Sum, $p$-value $=0.000$ and $p$-value $=0.000)$. 

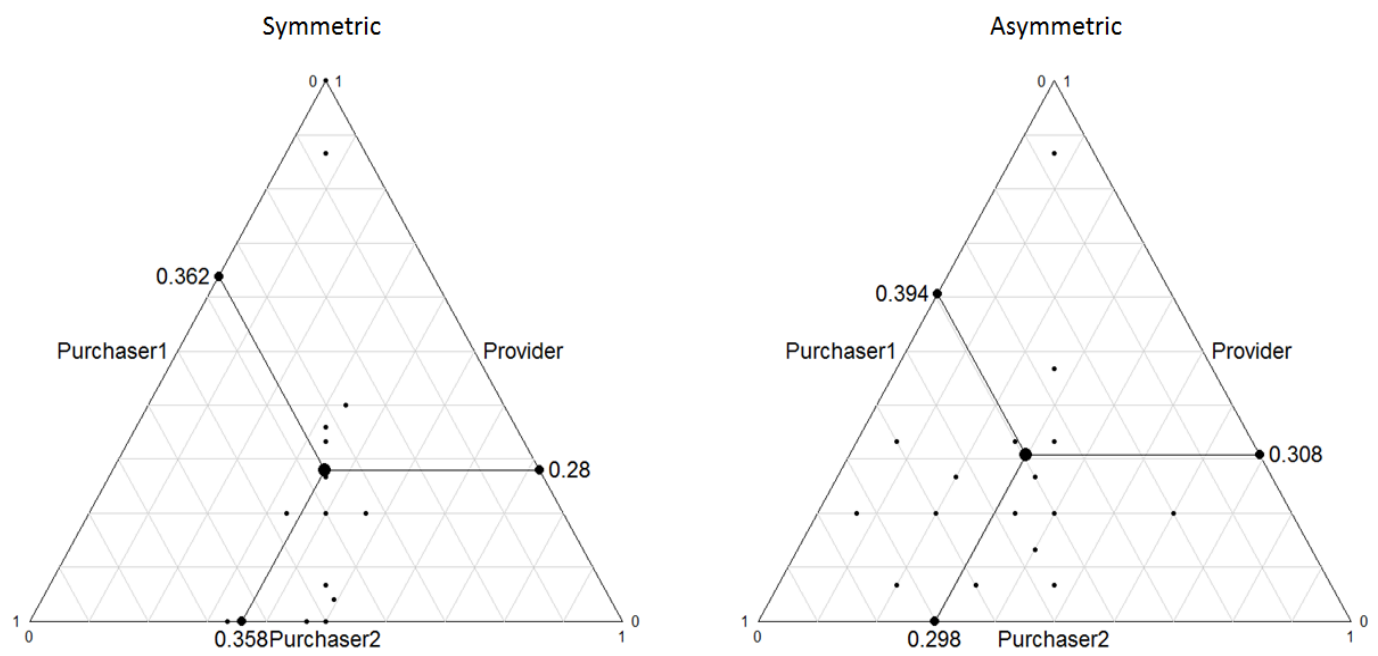

Figure 4. Ternary plot of the proportional split in the total surplus from the symmetric (1A) and asymmetric (2A) experimental treatments, with the lines showing the mean amount for each agent.

If the purchasers were attempting to share the surplus equally we would expect no differences between the division of surplus in Treatment 1A and Treatment 2A. Comparing Treatment 2A to $1 \mathrm{~A}$ using average division of surplus provides conflicting evidence. On the one hand, statistically significant differences are observable between the division of surplus for purchaser $2(35.8 \%)$ in the symmetric treatment and asymmetric treatment $(29.8 \%)$ (Wilcoxon-RankSum, $p$-value $=0.000$ ); on the other hand, there is no statistically significant difference between purchaser 1's surplus (Wilcoxon-Rank-Sum, $p$-value $=0.403$ ) despite an increase from $36.2 \%$ to $39.8 \%$. We are left with two possibilities: (i) the surplus is shared roughly equally or (ii) the payoffs are shared roughly equally. Since the default payments are the same for the two purchasers in Treatment 2A we cannot differentiate between those two hypotheses in this treatment, to provide further clarity we turn to Treatment $3 \mathrm{~A}$.

Treatment $3 \mathrm{~A}$ provides the same deal payments as Treatment $2 \mathrm{~A}$, the difference is the introduction of asymmetry into the default payment. Purchaser 1 with the deal payment of $£ 18$ also gets the high default payment of $£ 10.50$; purchaser 2 , with the low deal payment of $£ 12$ 
also gets the low default payment of $£ 4.50$. Accordingly, both purchasers stand to make the same gain from agreeing a deal, $£ 7.50$.

Now the subjects cannot simultaneously achieve equal division of surplus and equal payoffs. If purchasers are motivated by equal divisions of surplus then we would observe unequal payoffs, conversely if purchasers are motivated by equal payoffs then we would observe unequal divisions of surplus. Our results show a clear pattern-very unequal divisions of surplus and relatively equal payoffs. In Treatment 3A, purchaser 2 claimed a significantly larger share of the surplus, 55\%, compared to $19 \%$ for purchaser 1 (Wilcoxon-Rank-Sum, $p$ value $=0.000$ ). Figure 5 plots the division of surplus for Treatment $3 \mathrm{~A}$.

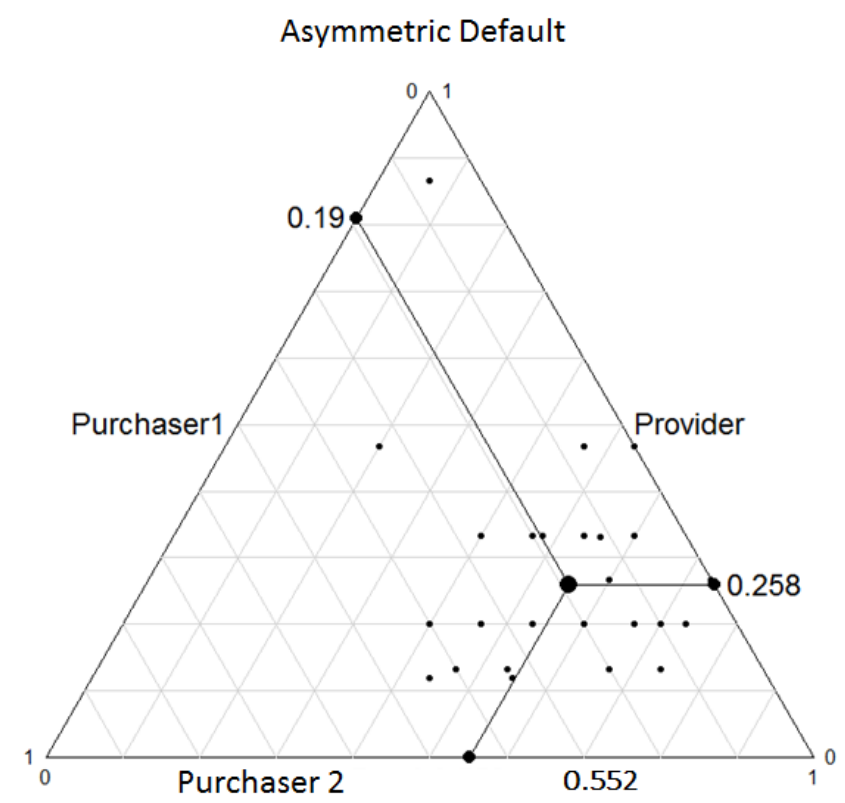

Figure 5. Ternary plot of the proportional split in the total surplus from the asymmetric default (3A) experimental treatments, with the lines showing the mean amount for each agent.

In Treatment 3A, it was not possible for the players to achieve equal payoffs unless purchaser 1 decided to accept a deal in which she received less than her default payment of $£ 10.50$; however, in our data we observe 3 such deals. It seems that, for some subjects, equal payoffs are so desirable that some purchasers are willing to accept less than their default payment in 
order to achieve equality of payoff with other group members. All other deals in Treatment 3A resulted in unequal payoffs, and on average, Purchaser 1 contributed significantly more to the payment (Wilcoxon-Rank-Sum, $p$-value $=0.000$ ).

Given full information, it seems that equal payoffs is a strong point of attraction for negotiation outcomes. In Treatment 3A, even though both Purchasers have the same gains from a deal, and therefore bring equal amounts of surplus to the negotiating table, purchaser 1 contributed significantly more to the deal and thus claimed a smaller share of the surplus, $19 \%$, with purchaser 2 claiming 55\%. This evidence agrees with previous experimental studies that found that even with asymmetric gains from a deal their subjects were drawn towards outcomes that equalized payoffs (Bruce and Clark, 2010a, b; Hoffman and Spitzer, 1985; Roth et al., 1981).

\subsection{Incomplete information.}

Treatments $2 \mathrm{~B}, 2 \mathrm{C}, 3 \mathrm{~B}$ and $3 \mathrm{C}$ include incomplete information. The deal payments are private information in $2 \mathrm{~B}$ and $3 \mathrm{~B}$, and the deal and default payments are private in $2 \mathrm{C}$ and $3 \mathrm{C}$. Treatments $2 \mathrm{~B}$ and $2 \mathrm{C}$ have the same deal and default payments as Treatment 2A, whereas, Treatments 3B and 3C have the same deal and default payments as Treatment 3A.

Our results provide no support for the hypothesis that incomplete information implies negotiations are more likely to result in failure. Comparing the proportion of successful deals in Treatment $2 \mathrm{~A}$ to the proportion of successful deals in Treatment $2 \mathrm{~B}$ and $2 \mathrm{C}$, and similarly $3 \mathrm{~A}$ to $3 \mathrm{~B}$ and $3 \mathrm{C}$, reveals no statistically significant differences between the proportions (Treatment 2: Fisher exact test, $p$-value $=1$, Treatment 3: Fisher exact test, $p$-value $=1$ ).

Our results provide some support for the hypothesis that incomplete information implies prolonged negotiation. For Treatment 2 an observable difference between the incomplete information treatments and full information treatment shows bargaining to be relatively harder; 
the average number of rounds of negotiation is 7.6 in Treatment $2 \mathrm{~B}$ and 8.2 in Treatment $2 \mathrm{C}$ compared to 4.6 in Treatment 2A (Figure 6).

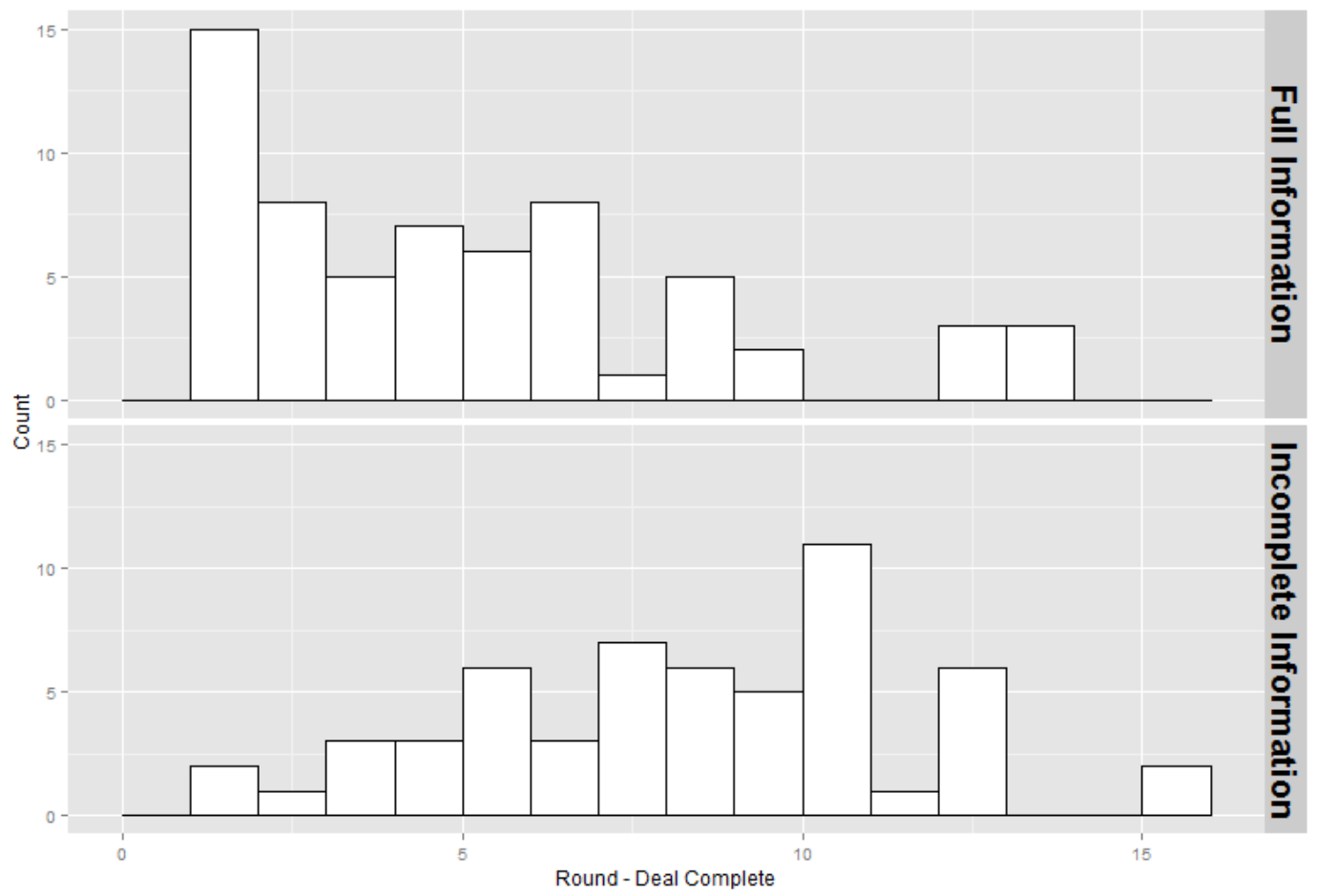

Figure 6. Number of rounds until deal completed for full information (2A) and incomplete information (2B 2C) experimental treatments.

The results show that with full information deals were completed significantly quicker for treatment 2 (Wilcoxon-Rank-Sum, $p$-value $=0.000$ ); however, those differences are not repeated when comparing Treatment 3A with 3B and 3C (Wilcoxon-Rank-Sum, $p$-value = 0.516). We therefore have some evidence to support the conclusion in Shupp et al. (2013) who found that with incomplete information bargaining was more prolonged but no support for their conclusion that that resulted in more failures to reach a deal.

Now consider Figure 7 which illustrates the division of contributions between the two purchasers and the division of surplus between the purchasers and the Provider for all asymmetric treatments with complete and incomplete information. Since purchasers did not know the other purchasers default payment in either Treatment $2 \mathrm{C}$ or $3 \mathrm{C}$ we claim that a 
reasonable assumption would be that the other purchaser had the same default payment. Under that assumption, we would expect no difference in the division of surplus between Treatment $2 \mathrm{~B}$ and $2 \mathrm{C}$ because the purchasers in treatment $2 \mathrm{C}$ would assume, in this case rightly, that they have equal default payments. At the same time, we would expect to see a difference between treatment $3 \mathrm{~B}$ and $3 \mathrm{C}$ because the assumption of equal default payments in Treatment $3 \mathrm{C}$ would be false. The division of surplus results support this hypothesis. A statistically significant difference was observable between the division of surplus in Treatment $3 \mathrm{~B}$ and $3 \mathrm{C}$ (WilcoxonRank-Sum, Purchaser 1: $p$-value $=0.009$, Purchaser 2: $p$-value $=0.011)$ but not Treatment 2B and 2C (Wilcoxon-Rank-Sum, Purchaser 1: $p$-value $=0.387$, Purchaser 2: $p$-value $=0.755)$.

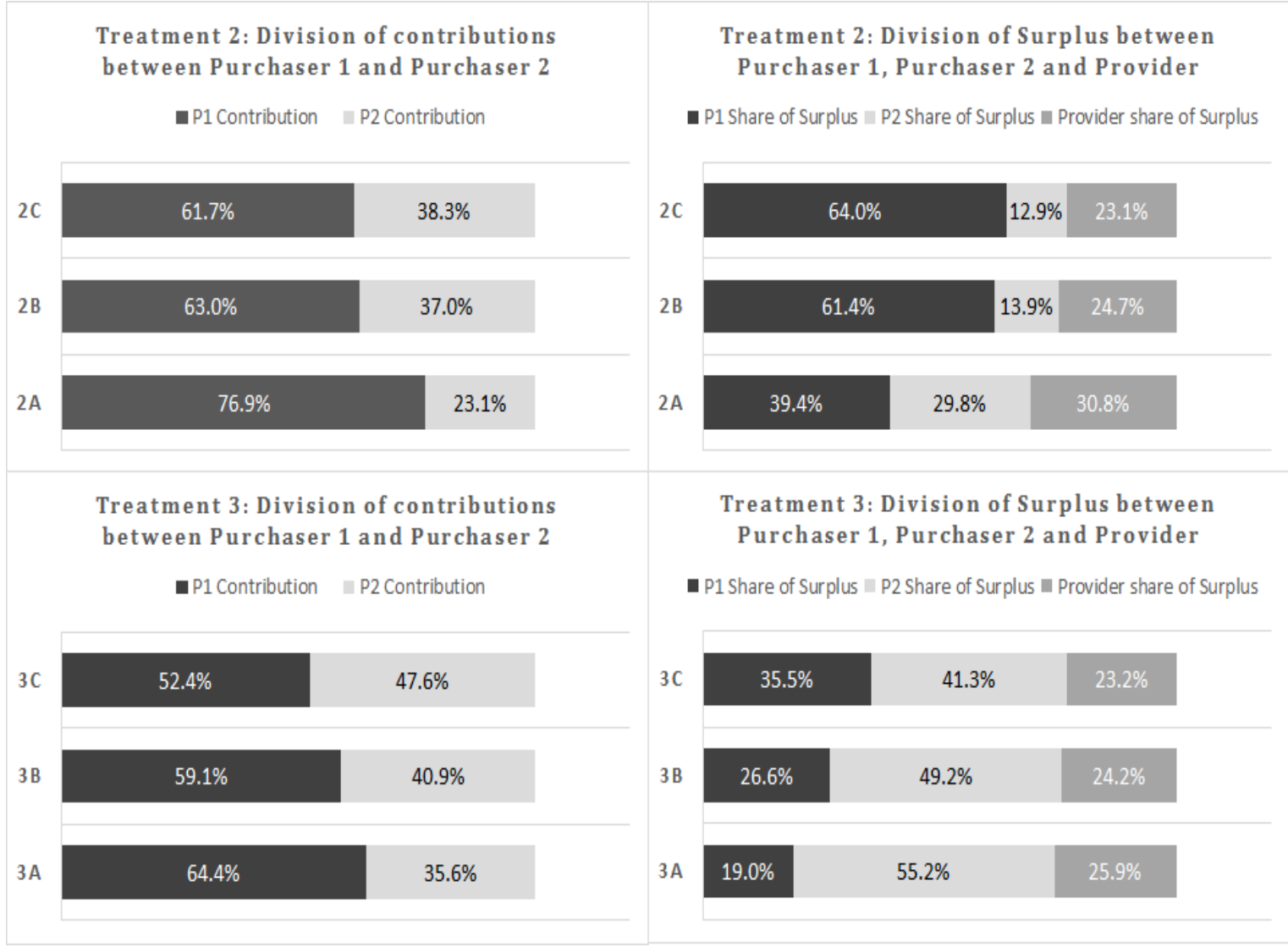

Figure 7. Division of contributions and division of surplus for asymmetric deal and asymmetric default treatments (Treatments: 2A, 2B, 2C, 3A, 3B, 3C).

Finally, we explore differences in the contributions in Treatment $2 \mathrm{C}$ compared to Treatment 3C. In Treatment 3C the purchasers' contributions to the payment are close to equal, Purchaser 
1 contributes on average $52.4 \%$ whereas Purchaser 2 contributes $47.6 \%$. Therefore in the absence of knowledge about the other purchaser's deal and default payment it seems the purchasers are motivated by equal contributions. However, there is a large difference in contributions observable in Treatment 2C, Purchaser 1, 61.7\% and Purchaser $238.3 \%$. This suggests a fundamental difference between the deals completed in the two fully private information treatment. One possible explanation comes from Zwick and Mak's (2012) costbenefit proposal that because Purchaser 1 has more to gain from a deal in Treatment $2 \mathrm{C}$, they will be more willing to compromise and so contribute a higher share.

\subsection{Uncertainty}

Treatments 4+ and 4- are full information treatments but the actual deal benefits are uncertain. The key design feature that distinguishes Treatment 4+ from 4- is that in Treatment 4+ deal payments are positively correlated; both Purchaser 1 and Purchaser 2 get their higher payment in 'state of the world a' and their lower payment in 'state of the world b'. In contrast, in Treatment 4- deal payments are negatively correlated; Purchaser 1 realises their high payment when Purchaser 2 realises their low payment and vice versa. The payments are designed to maintain asymmetry between the purchasers; Purchaser 1 has opportunities for deal payments that are as large if not larger than those of Purchaser 2. For both purchasers the deal payment in one 'state of the world' is larger than that in the other.

Despite the added complexity, participants were able to reach deals in a similar number of rounds to other asymmetric full information treatments. Figure 8 shows the number of negotiation rounds in the stochastic treatments compared to the deterministic treatments (Treatments: 2A, 3A). The results show no statistically significant differences in the number of rounds to complete a deal (Wilcoxon-Rank-Sum, $p$-value $=0.247$ ). 


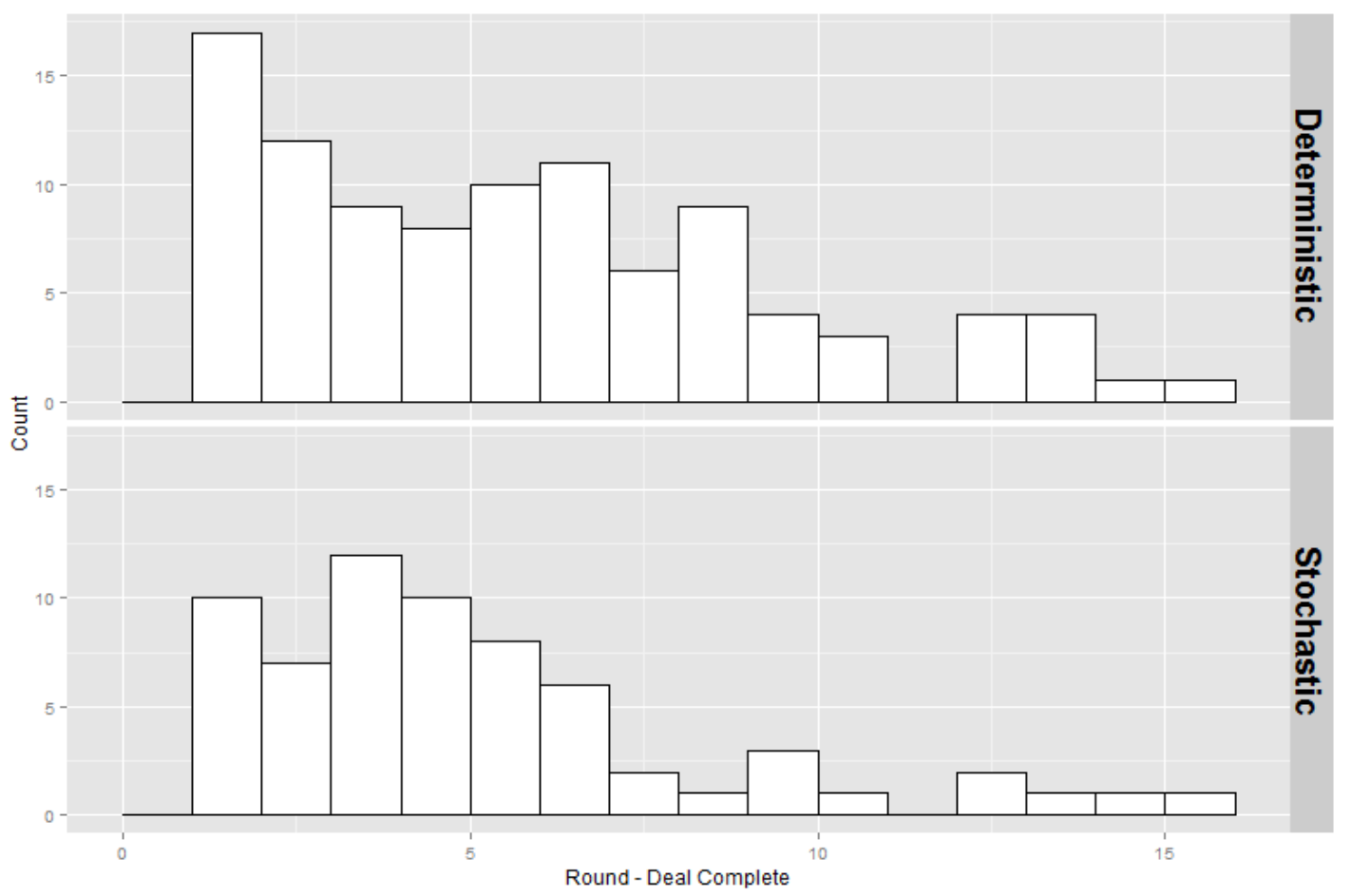

Figure 8. Number of rounds until deal completed for deterministic $(2 \mathrm{~A}, 3 \mathrm{~A})$ and stochastic (4+ 4-) experimental treatments.

Consider now Treatment 4+ in Figure 9. Rather than offering the Provider the same payment no matter what the 'state of the world', the deal that the purchasers agree to is one where they pay the Provider more (£11.06) if they both get their high payments ('state of the world a') and less (£8.16) if they both get their low payments ('state of the world b'). In effect, the purchasers push some of the risks of a bad outcome onto the Provider. In contrast, in Treatment 4- the Provider gets very similar payments in both 'states of the world', £9.70 and $£ 9.73$. The purchasers arrange their payments quite differently; compared to the positively correlated case, they pay relatively more when they enjoy the 'good state of the world' and relatively less when they enjoy the 'bad state of the world'. Essentially, in Treatment 4- the purchasers share the risk of different possible outcomes between themselves rather than with the Provider. 


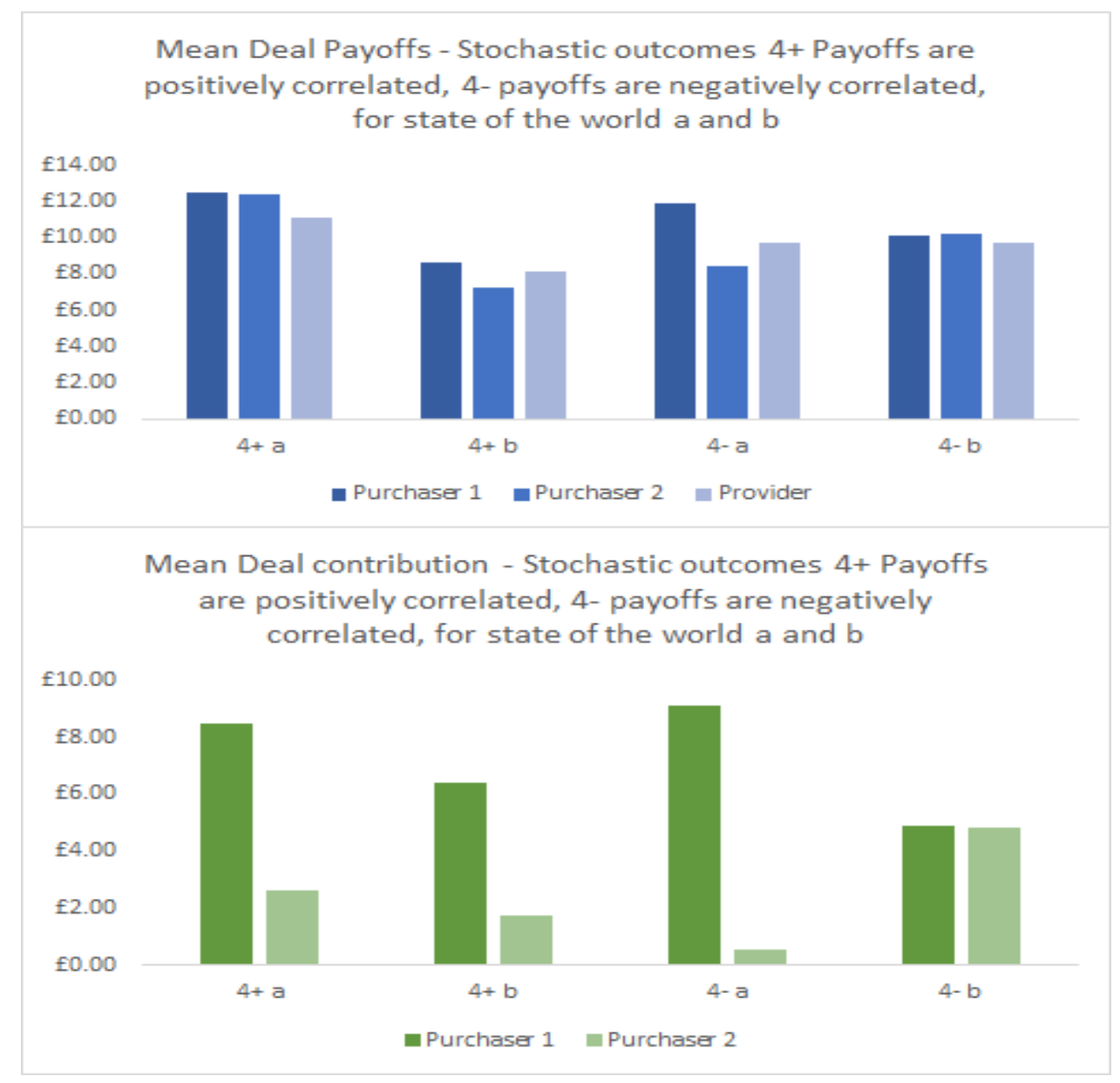

Figure 9. Deal payoffs and contributions from the stochastic benefit treatments

(Treatments: 4+ a, 4+ b, 4- a, 4- b).

Furthermore, the stochastic treatments provide additional evidence that the participants are drawn to equal payoffs when information is complete. The top panel of Figure 9 shows the mean deal payoffs for Treatments 4+ and 4- are very similar for each participant in all of the stochastic treatment scenarios, this is achieved despite the large differences in the potential deal benefits. The bottom panel of Figure 9 shows large differences in contributions in order to achieve those equal or near equal payoffs.

\section{Conclusions}

As illustrated by the paucity of real world examples, the collective action problem acts to inhibit the self-organisation of multiple-purchaser PES schemes. In this paper, we report on a series of laboratory experiments designed to explore the role of negotiation in addressing that issue. 
Perhaps the central message of our research is that, despite incentives to free-ride, negotiation with binding pre-commitment overcomes the free-rider problem and drives successful formation of multiple purchaser PES. Of 413 experimental negotiations carried out under a variety of complicating conditions, participants managed to reach agreement on 365 occasions (88\%). A clear implication of that finding is that the development of multiple-purchaser PES markets may be enabled simply by creating the appropriate institutions and legal framework through which negotiations and mutual commitments to payments can occur. In that regard, institutional design for multiple purchaser PES might well be informed by institutions developed for collective action in the context of international cooperation (Koremenos et al., 2001) cooperation across government (Feiock, 2013) or in the communal institutions for the government of the commons (Ostrom, 2012).

The deals reached amongst our experimental participants reveal that, given full information, equal payoffs for purchasers are a strong point of attraction, a finding that supports results from existing studies (Bruce and Clark, 2010a, b; Hoffman and Spitzer, 1985; Roth et al., 1981). For the provider, whose negotiating power is reduced to the role of a price taker, we find outcomes that indicate agreement to receipt of an amount that is less than that realised by the purchasers. Again this conforms with experimental evidence from ultimatum and alternating bargaining games (Roth, 1995; Schmitt, 2004). Of course, our results concern a PES market with a single provider; the existence of alternative competing providers would only act to erode providers' negotiating power.

Our experiments show that under conditions of uncertainty, allowing purchasers to propose payments that are contingent on the level of realised ES flow, leads participants to seek out deals that share the risk of bad outcomes across the three parties. We suspect that uncertainty over realised gains is a major factor in all PES and that mechanisms for sharing risks across purchasers and providers will be an important factor in encouraging market participation. For 
inspiration, PES scheme designers might look to the mature literature in economics on the design of risk-sharing and incentive contracts (Laffont and Tirole, 1993; Shavell, 1979). In our experiments, the opportunities for risk sharing were most readily realised when the stochastic ES flows accruing to the two purchasers were negatively correlated. Under those circumstances, one purchaser would do well when the other did badly such that the two purchasers could adjust their contingent contributions to ensure that their payoffs and the payoff to the provider remained stable no matter what the ultimate state of the world. Opportunities for such risk sharing within real world PES schemes may be limited by the fact that the ES benefits arising from PES-funded interventions are commonly positively correlated (Raudsepp-Hearne et al., 2010); when, on a particular occasion, the scheme delivers poor returns on one ES, it tends also to deliver poor returns on other ES. Under such circumstances, one possibility is to share the risks outside the PES scheme through private or publically-funded insurance. For example, providers could insure against poor returns from a PES in which their payments are linked to the levels of ES their actions deliver in the same way that farmers insure against poor crop yields through agricultural crop insurance programs (Barnett, 2000).

Our research also reveals that asymmetry in purchasers with regards to financial means and gains from a deal tends to result in lengthier negotiations. Translated in to real world contexts, that finding is suggestive of asymmetry inducing higher transaction cost in reaching agreement. Delays in achieving a deal are also observable under conditions of incomplete information. It follows that in real world multiple-purchaser PES, successful outcomes may well be facilitated by negotiating institutions that require purchasers to reveal their potential gains. Of course, such rules would be hard to enforce given strategic incentives to under-report; we find that revelation is expensive for the purchaser that stands to gain the most, their contributions are higher when they reveal the level of their potential gains to other purchasers. The negative impacts of this information dilemma (failure to discover mutually beneficial agreements) have 
been studied in other negotiating contexts (Murnighan et al., 1999; Thompson and Hastie, 1990). A possible solution to the information dilemma is offered by the introduction of an independent broker acting as a mediator in negotiations (Carnevale and Pruitt, 1992). Indeed, it has already been recognised that intermediary involvement can play a crucial role in PES success. Sattler et al. (2013) report that in a sample of 22 successful PES schemes, 82\% involved an intermediary, most often an independent non-governmental organisation. We suspect that the intervention of an intermediary may be even more important in establishing multiple-purchaser PES. In this context, the intermediary's role is not limited to brokering agreements between providers and purchasers but also in brokering negotiations between purchasers regarding their relative contributions to PES payments.

Multiple-purchaser PES schemes have the potential to deliver numerous benefits including cost-sharing, expanded financing and broadened scope. Realising those benefits requires finding a solution to the collective action problem. Providing the institutional framework that enables purchasers to negotiate contributions to PES payments, perhaps facilitated by an independent intermediary, is likely to be central to that undertaking. 


\section{Acknowledgements}

We gratefully acknowledge the input of Professor Alastair Munro in the initial stages of this project and for his help in outlining the form of the model presented in the appendix. This project was carried out as part of the Defra Payments for Ecosystem Services (PES) Pilot Research Projects: River Fowey Improvement Scheme [NE0131]. It was also supported by a University of East Anglia studentship. Funding support is gratefully acknowledged. We thank participants at the 2014 World Congress of Environmental and Resource Economists conference, Istanbul. 


\section{Appendix A: Experiment Instructions and walkthrough}

\section{Welcome}

- Welcome to the experiment! We are about start.

- Before we start, please could you put away anything that you have on your desks and turn off and put away your mobile phones. We will be paying you for your participation in this experiment and in return we expect that you will focus on that task for the next hour to an hour and a half.

- During that time you and the other participants in the room will be undertaking a series of 7 tasks on the computers.

- In those tasks you will be teamed-up with 2 other participants to make a group of THREE people. You won't know who the other people are in your group and the members of your group will change from task to task.

- Each task will involve you negotiating with the other members of your group in an attempt to agree on a DEAL. Whether you reach a deal and what particular deal you agree upon will determine how much money you will be entitled to from that task.

- On your desk, you should have a document outlining the key elements of each task. You can refer to that as we walk you through how a task will be played out on your computer.

\section{Task and Round Counters and Timer}

- To do that, we are going to begin by introducing you to the basic elements you will see on the screen in each task. So, to the top left of your screen you should see a task counter, this will update as you work through each of the seven tasks.

- In each task you will go through a series of rounds of negotiation with the other members of your group. The counter to the top right will tell you which round of negotiation you have reached.

- The final element at the top of the screen is a timer. You should now be able to see that counting down. 
- During the negotiations you will have to make decisions, but you will only have limited time to come to those decisions ... sometimes as little as 10 seconds. As soon as it is your turn to make a decision, the COUNT DOWN begins. If the countdown reaches zero then you will TIME OUT and forfeit your opportunity to make that decision ... which may have an impact on how much you get paid. As a result, you will have to think quickly during the experiment.

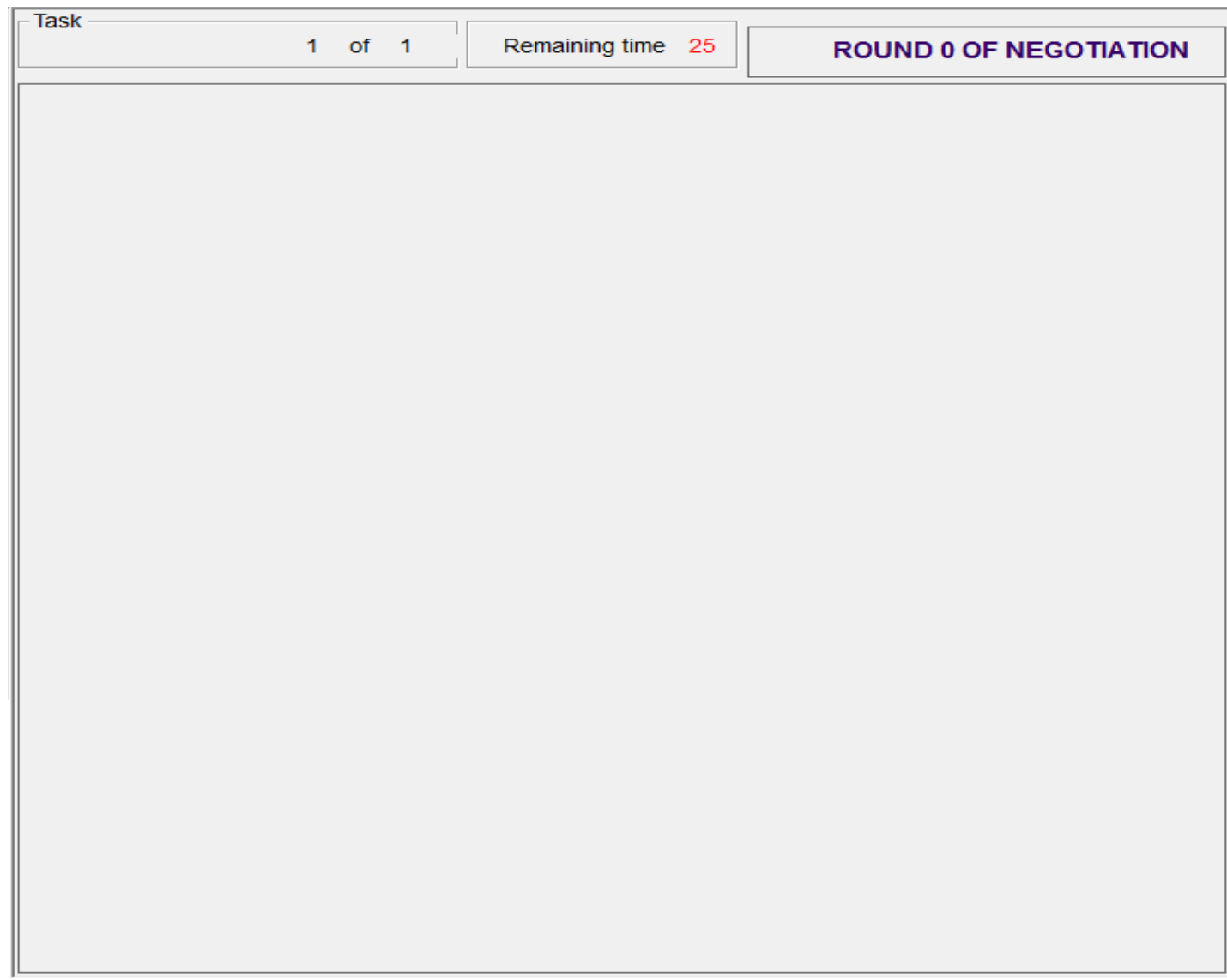

\section{Default Payment}

- In each task, each person in a Group of 3 is allocated to take the role of PLAYER 1, PLAYER 2 or PLAYER 3 ... which particular role you take on will change from task to task.

- Each player in your group starts out entitled to the same DEFAULT PAYMENT. This is the payment that you will get if your negotiations fail and the three members of your group cannot agree to a DEAL.

- The first box on your screen shows this payment. For all the tasks you will undertake today your DEFAULT PAYMENT will be $£ 7.50$. 
- Alternatively, provided each of the 3 players in your group agrees to the idea, then instead of each member getting their DEFAULT PAYMENT they will get their DEAL PAYMENT instead.

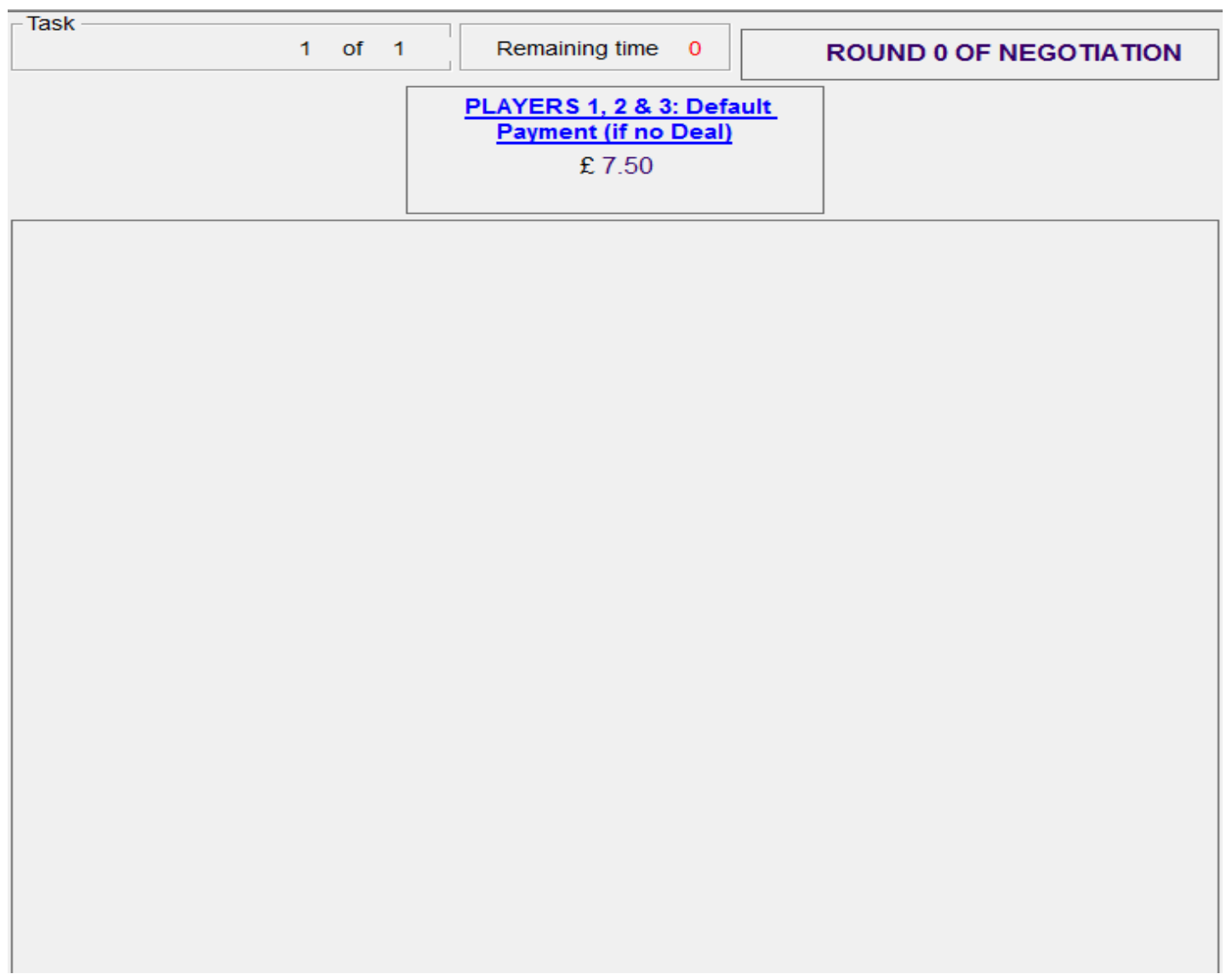

\section{Deal Payment Players 1 \& 2}

- The Deal payments for Players 1 and 2 are shown in the two boxes that have now appeared on your screen.

- Notice that the role that you will be playing in any particular Task will be indicated to you by highlighting the title of that Player's Deal payment box in Blue. In this example, you are Player $2 \ldots$ though remember which role you play will change from task to task.

- If you agree to a deal, then in some tasks there may be more than one possible outcome and you won't know which of those outcomes will turn out to be your actual Deal payment until after the negotiations have finished. We label those different Outcomes A and B. In the task we are considering here, however, there is only one outcome ... outcome A. Accordingly, as Player 2 in this task, if your group were to agree to a Deal then you can be $100 \%$ certain that you will be due a Deal payment of $£ 19$. The first 
few tasks will be just like this. Don't worry, we'll come back and talk you through Deals with more than one Outcome before you start on those tasks.

- Notice that as Player 2, your Deal payment of $£ 19$ is considerably higher than your Default payment of $£ 7.50$. The same is true for Player 1 who stands to make $£ 14$ if a deal is agreed as opposed to the Default payment of $£ 7.50$. Indeed, in all the tasks Players 1 and 2 will always have Deal payments that are larger than their Default payments and, therefore, will be keen for all 3 Players to reach an agreement that allows them to claim their Default payments.

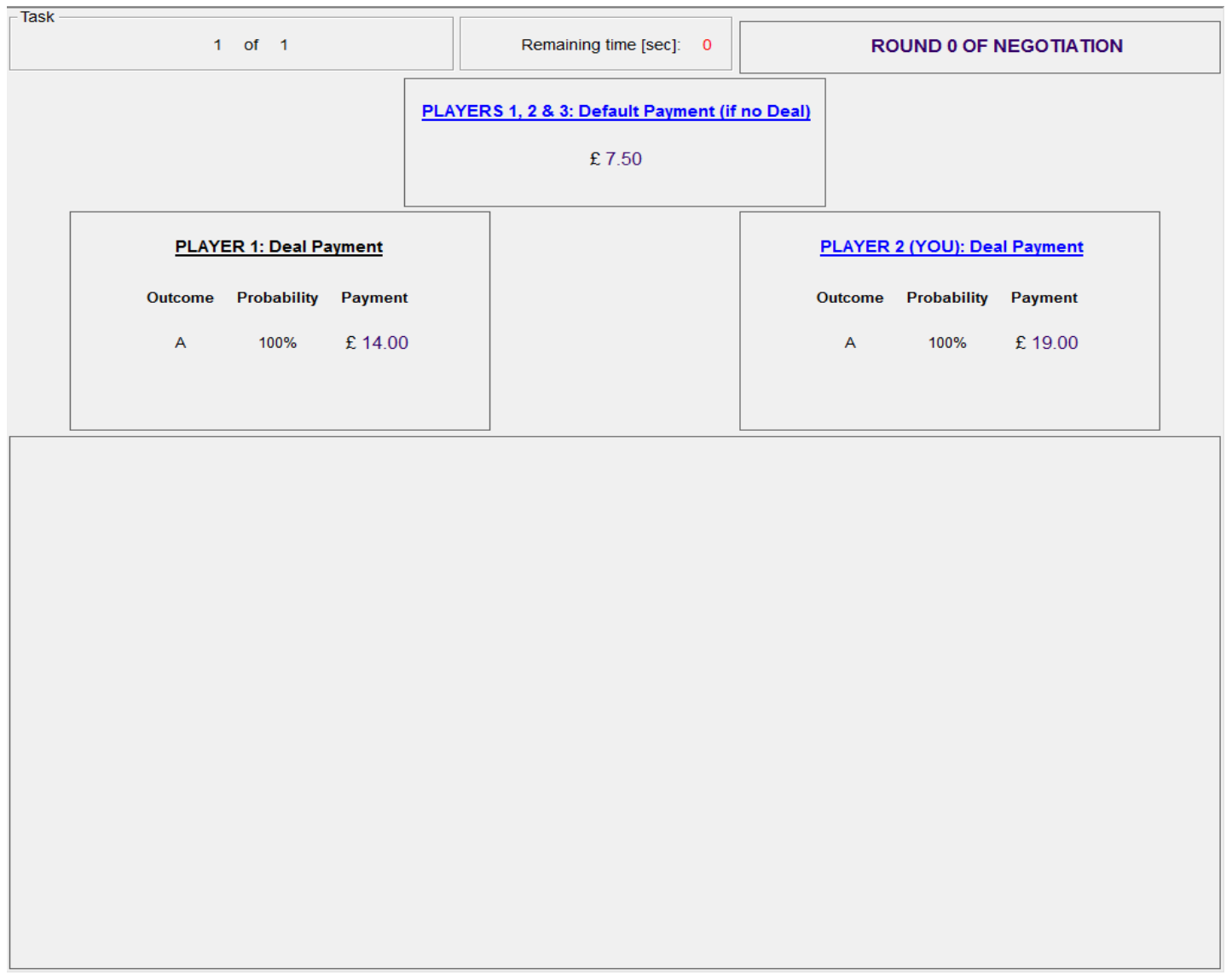

\section{Deal payment Player 3}

- The key obstacle in reaching an agreement, however, is that the Deal payment for Player 3 is always zero. You should be able to see the Deal payment box for Player 3 at the bottom of your screen.

- For that reason, the only way agreement can be reached is if the Players can negotiate a DEAL. That Deal involves Players 1 and 2 committing to share enough of their Deal payments with Player 3 so as to convince Player 3 that it is worth their while agreeing to the Deal. 
- Negotiations in a task always begin with Player 1 making a PROPOSAL to Player 2. In that Proposal Player 1 suggests how much of their own Deal payment and how much of Player 2's Deal payment should be offered to Player 3. The sum of those two suggested contributions is the proposed payment to be made to Player 3 .

- Player 1's Proposal is passed on to Player 2 who must decide whether to REJECT or ACCEPT it. If Player 2 rejects the Proposal, they may get the chance to offer a COUNTER PROPOSAL ... and negotiations may go back and forth between Players 1 and 2 until they finally agree on a Proposal to offer to Player 3.

\section{Reject Proposal}

- In this walk through, we join the negotiations part way through. In the left hand side of the Proposal Accept/Reject Box that has just appeared on your screen the Proposal History table which lists the last 5 proposals that have passed between Players 1 and 2 .

- In this case, Player 1 started the negotiation by proposing that she pay $£ 2.50$ towards a payment to Player 3 while you, as Player 2, should contribute a further $£ 7.50$... giving a total Payment to Player 3 of $£ 10$. In this case, you rejected that proposal (which is why it is coloured red in the table) and suggested a counter proposal in which Player 1 paid $£ 5$ and you paid $£ 4$ (a total Payment to Player 3 of $£ 9$ ). Unfortunately, Player 1 wasn't happy with that proposal and rejected it, coming back with another proposal in which she pays $£ 4$ and you pay $£ 8$. Since that is the current proposal on the table, it is coloured black in the Proposal History table.

- You can see that current proposal written out in large in the right hand side of the box in red text and next to it a red decision button with the word "rejected" written on it. This is exactly what the screen will look like when you first receive a proposal to consider. The fact that the decision button says "rejected" and the text is red indicates that you currently intend to reject that proposal.

- By clicking on that decision button you can indicate, instead, that you would like to Accept the Proposal instead. Go ahead and try that now.

- Notice that the text has gone green and the decision button is now grey with the word "accepted" on it. That indicates that you currently intend to accept the proposal.

- To register your decision you MUST press on OK. Whatever word is written on the button when you press OK will be the decision you register in the negotiation. If you 
fail to press OK then the computer will not register your decision and just assume that you have rejected the Proposal.

- Now click on the decision button again to change it back to rejected. Observe the text that appears next to the OK button. This text is a warning, informing you that should you click $\mathrm{OK}$ and thereby reject the proposal then you run the risk that the NEGOTIATIONS WILL FAIL. If that happens then no Deal is reached and each player will have to content themselves with their DEFAULT PAYMENT.

- In this case the Probability of such a failure happening if you decide to reject the proposal is 1 in 30. If you were to go ahead and press OK, the computer would use its random functions and those odds to establish whether you have been unlucky and the negotiations have failed. During a negotiation those probabilities start out low at 1 chance in $500 \ldots$ by the time 5 rejections have been made in a negotiation that probability is up to 1 in $100 \ldots$ by the tenth rejection 1 in $15 \ldots$ and by the fifteenth more than 1 in 2.

- Making this decision even harder is the fact that you have to do it against the clock. We've disabled that for the purposes of this walk through, but when you start the real tasks, as soon as you see this screen the countdown clock will start clicking down. If you haven't pressed OK to register your decision by the time the countdown clock reaches zero, the computer will simply assume that you are rejecting the proposal.

- Let's, assume that you are sufficiently unhappy with this Proposal that you are prepared to take the risk of rejecting it. Make sure the decision button says "rejected" then press OK. Actually we've disabled that button as well, but we will move you on automatically from our master program. 


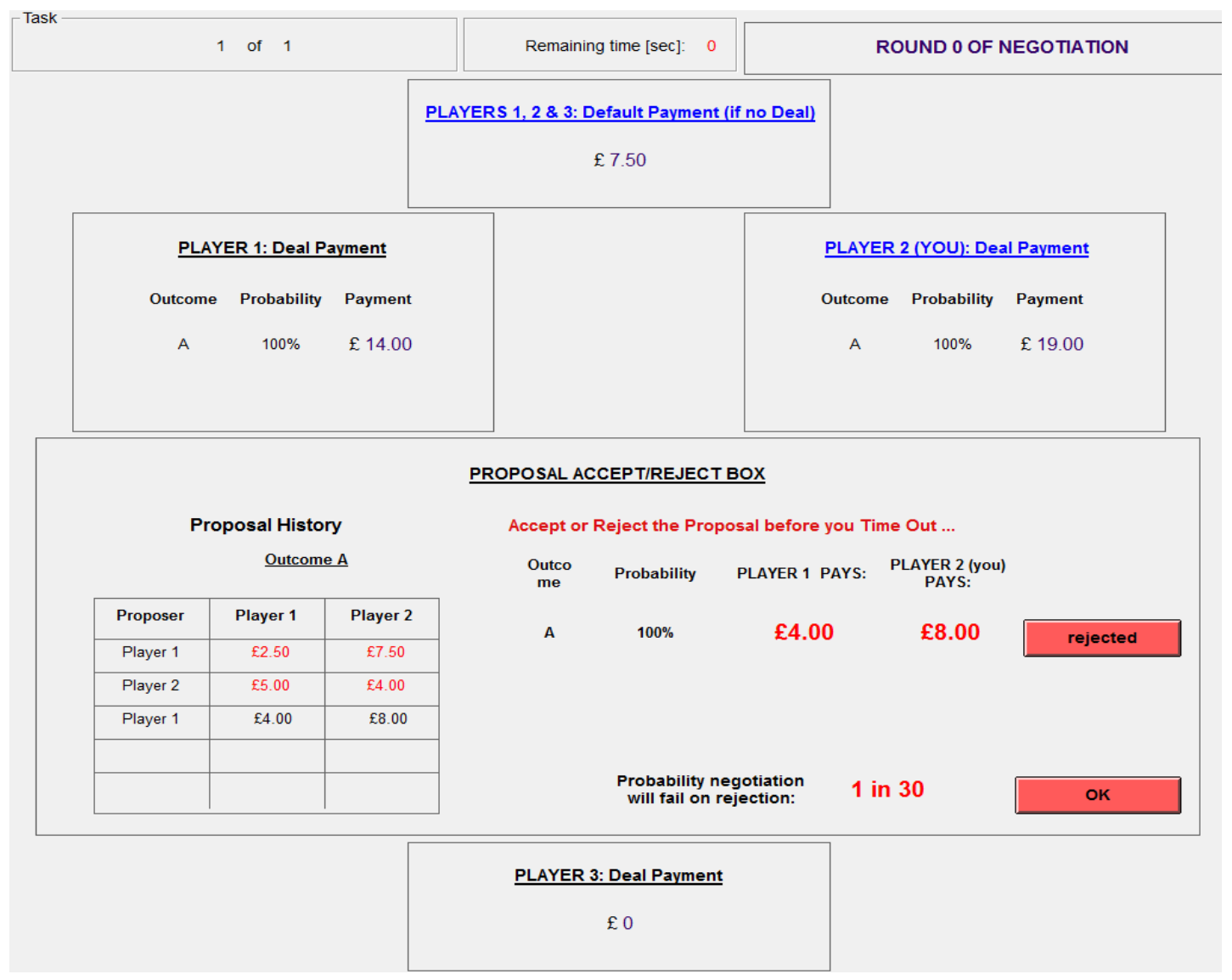

\section{Make a Proposal}

- In this case you got lucky and the negotiations did not fail. You now have the opportunity to make a proposal of your own.

- To make your counter proposal you fill in the amounts that you think that you and the other player should make to Player 3 in the boxes provided. In entering those amounts, be aware that the units are in $£$ s... if you want to include a pence amount (which you are perfectly entitled to do) you will have to enter it after a decimal point.

- Since these amounts will be paid for out of Deal payments you will never be able to suggest an amount that exceeds a Player's Deal payment.

- Please fill in the boxes with the following proposal: Player 1 pays $£ 5$, you pay $£ 6$. Now press enter to register your proposal. Notice that in deciding on a proposal, you will again be up against the clock. If the countdown reaches zero before you have pressed the Enter button, then the computer will simply assume that your proposal is that you both pay $£ 0$ to Player 3.

- Go ahead and press Enter to send you proposal off to Player 1 for them to consider ... though again notice that for the purposes of this walk through that we have disabled the 
Enter button and also have got the computer to ensure that you entered the amounts $£ 5$ and $£ 6$.

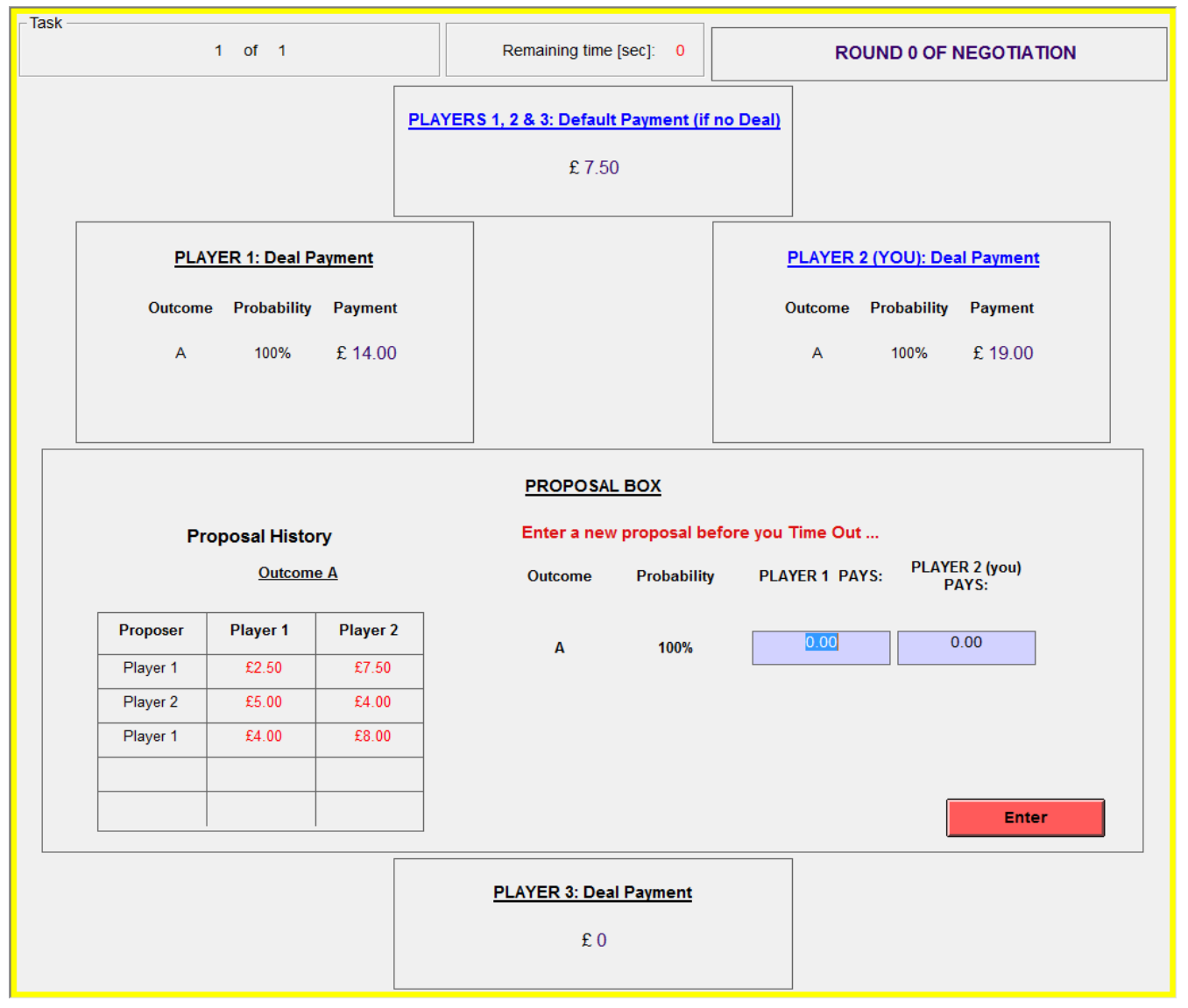

\section{Waiting for the Other Player to Consider a Proposal}

- Once you have sent your proposal to Player 1, you will move on to a waiting screen. This shouldn't take too long, but please do remain patient ... there's nothing more you can do until Player 1 decides whether to accept or reject your proposal.

\section{Accept Proposal}

- In this case Player 1 decided to reject your proposal. You all got lucky in that the negotiation did not fail when they pressed reject ... and now Player 1 has come back with a new Proposal. In this Proposal Player 1 pays $£ 4.50$ and you contribute $£ 6.50$ towards a combined payment to Player 3 of $£ 11$.

- Notice that the Proposal History table has been updated to show your last proposal ... which Player 1 rejected ... and Player 1's new proposal.

- Notice also that the risk of the negotiations failing if you reject has also gone up from 1 in 30 to 1 in 15 . 
- Let's imagine that you are now happy with the proposal and don't want to take the risk of rejecting.

- Toggle the decision button so it reads "accepted" and then press OK to accept the proposal and then we will move you on to the next screen.

\section{Waiting for Player 3 to Consider an Offer}

- The proposal that you have agreed to with Player 1 is now sent over to Player 3 to consider. You will now have to wait to see whether Player 3 is going to accept your Offer.

- If Player 3 does accept your offer, then everyone has consented and a Deal is done. If Player 3 rejects your Offer then you may get the chance to enter into fresh negotiations with Player 1 to see if you can agree to another Offer to put before Player 3.

\section{Player 3 waiting for an Offer}

- Again, if you are Player 3, please be patient ... it may take Players 1 and 2 a few rounds of proposal and counter-proposal before agreeing on an offer ... provided negotiations don't fail before they reach an agreement.

\section{Accept/Reject Offer}

- When (and if) an offer arrives, Player 3 will see a screen containing an Offer Accept/Reject Box just like this. To the left is a table listing the offers that have been made to Player 3 in this task. To the right you can see the current offer and buttons allowing Player 3 to accept or reject that offer.

- Notice that Player 3 only sees the total amount that Players 1 and 2 have agreed to pay, not their individual contributions.

- The buttons on this screen work in much the same way as those we looked at previously. When the screen first appears to Player 3, the decision button will say "rejected" indicating an intention to reject the Offer. Again, rejecting an offer comes with a risk of the negotiation failing. That risk is written next to the OK button.

- For the sake of argument, let us assume that you, as Player 3, are happy enough with this offer to think that it is not worth taking the risk of rejecting. Toggle the decision button so that it goes from "rejected" to "accepted", the text of the Offer should go green and, since you are now not planning to reject, the risk information disappears. 
- Again in the real tasks you will be making this decision against the clock and you will have to hit the OK button to register your decision before the countdown times out.

- Press OK now ... though remember for the walk through we've disabled that button and will move you on from our control program.

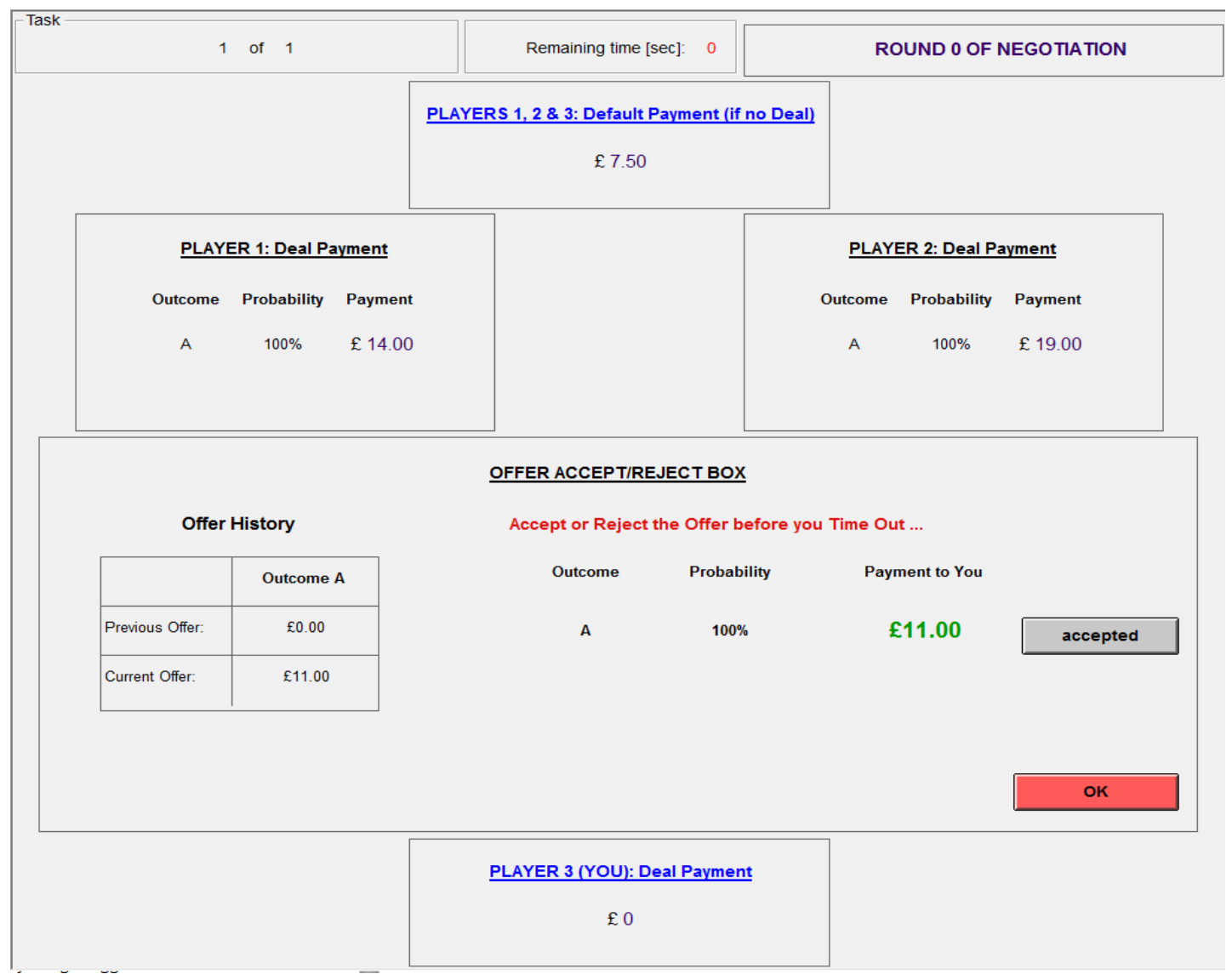

\section{Deal Done Screen}

- Since Player 3 has accepted an offer made by Players 1 and 2, this task ends with all three players agreeing to a deal. In this case, Player 3 has foregone the fall-back payment of $£ 7.50$ in favour of the $£ 11$ offered by Players 1 and 2 . If, at the end of the experiment, this task was picked as the one as the one that counts for real for Player 3, then this will be the amount of money they earn from participating in the experiment.

- As a deal was done by this group, each will now see a screen showing what they stand to gain from that task.

- Before they can move on to the next task, they will have to wait until all the other groups finish. Once everyone has completed the task, the next task begins by teaming you up with a different set of two people to form a new group. 


\section{Stochastic treatment walkthrough}

- We are now moving on to another set of tasks which are slightly more complicated than those you have just done in so much as the Deal payments for Players 1 and 2 can take one of two possible values and which of those is the actual value is not known during the negotiations.

\section{Information Boxes}

- Those two possible Deal payments are shown as Outcome A and Outcome B in the information boxes for Players 1 and 2. Notice that Player 3 always has a Deal payment of $£ 0$ whatever the outcome.

- While you do not know which outcome will be the actual outcome, you do know that there is exactly half a chance ( $50 \%$ chance) it will be Outcome A and half a chance it will be Outcome B. In this case, if it turns out to be Outcome A, your Deal payment as Player 2 will be $£ 17$ while the Deal payment for Player 3 will be $£ 20$. If, on the other hand it turns out to be Outcome B, your Deal payment will be $£ 11$ and Player 1's will be $£ 10$.

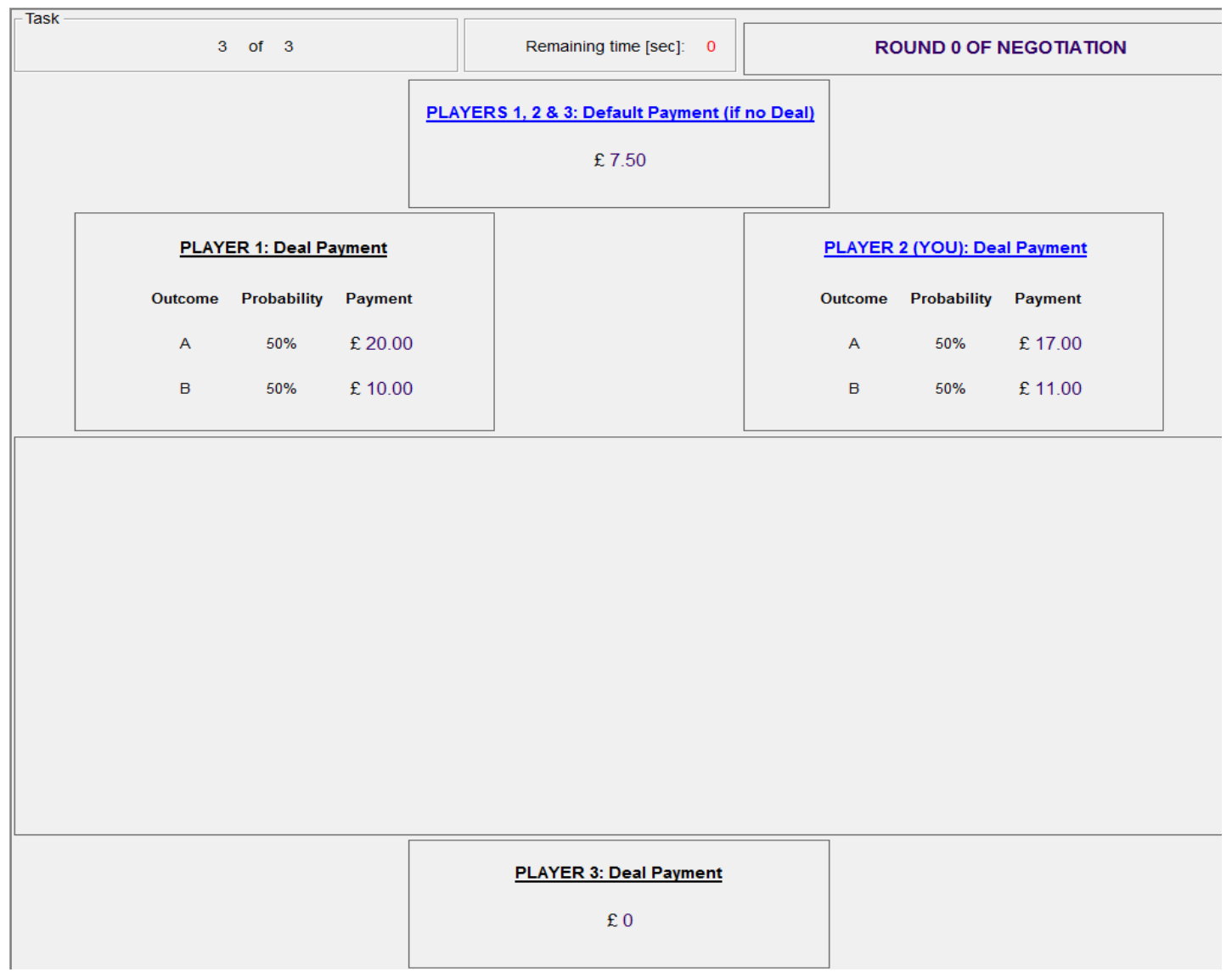

\section{Proposal Screen}


- Now in making a Proposal you must consider what payments you think should be made to Player 3 in the event of Outcome A and what payments should be made to Player 3 in the event of Outcome B. You must fill those amounts in the boxes provided and then press Enter to send you Proposal to the other Player to consider. Again you will be making your decisions against the clock.

- In deciding on those amounts bear in mind that Player 3 might be prepared to take some of the risk and accept an offer in which payment in one of the outcomes is below $£ 7.50$, provided the payment in the other outcome was sufficiently high that they thought taking that risk was worthwhile.

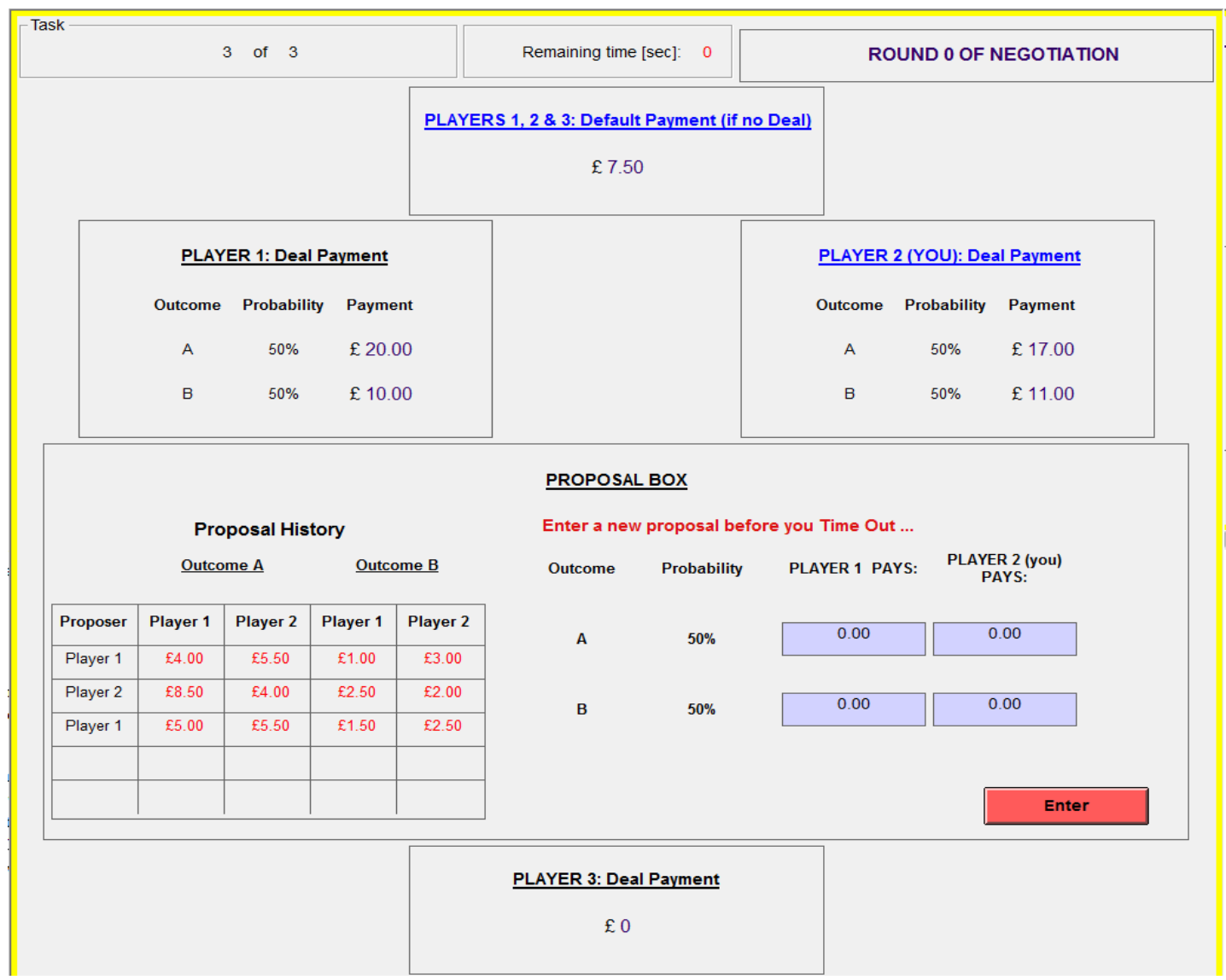

\section{Screen: Proposal Screen}

- When you receive a Proposal the screen will now look like this. In making your decision you have a separate decision button for each Outcome. Accordingly, you could accept the proposed payments in Outcome A, but reject those for Outcome B.

- Try toggling the decision buttons for the two Outcomes to "accepted". You should see the text of the proposal for an Outcome going green, when you toggle the decision button for that outcome to "accepted". 
- Notice that the risk associated with reject only disappears when you have accepted the Proposal for both Outcomes. If you were to do that then, the proposal would be passed on to Player 3 for their consideration.

- Alternatively, you may decide that you are happy with the payments for one Outcome, but not those for the other. In that case, the Proposal would be rejected and your decisions would be recorded in the Proposal History table to the left of the screen.

- For example, in the second to last row of the Proposal History table, you can see how Player 1 reacted to your last Offer. You suggested that in the event of Outcome A that they should pay $£ 7.30$ and that you should pay $£ 4.50$. They didn’t agree with that and hence those numbers are coloured red in the table. In contrast, you suggested that in the event of Outcome B that you should both pay $£ 2.50$. They accepted that part of the proposal and hence those numbers are coloured green in the table. Indeed, they have kept those suggested payments as part of the proposal they have sent back to you to consider.

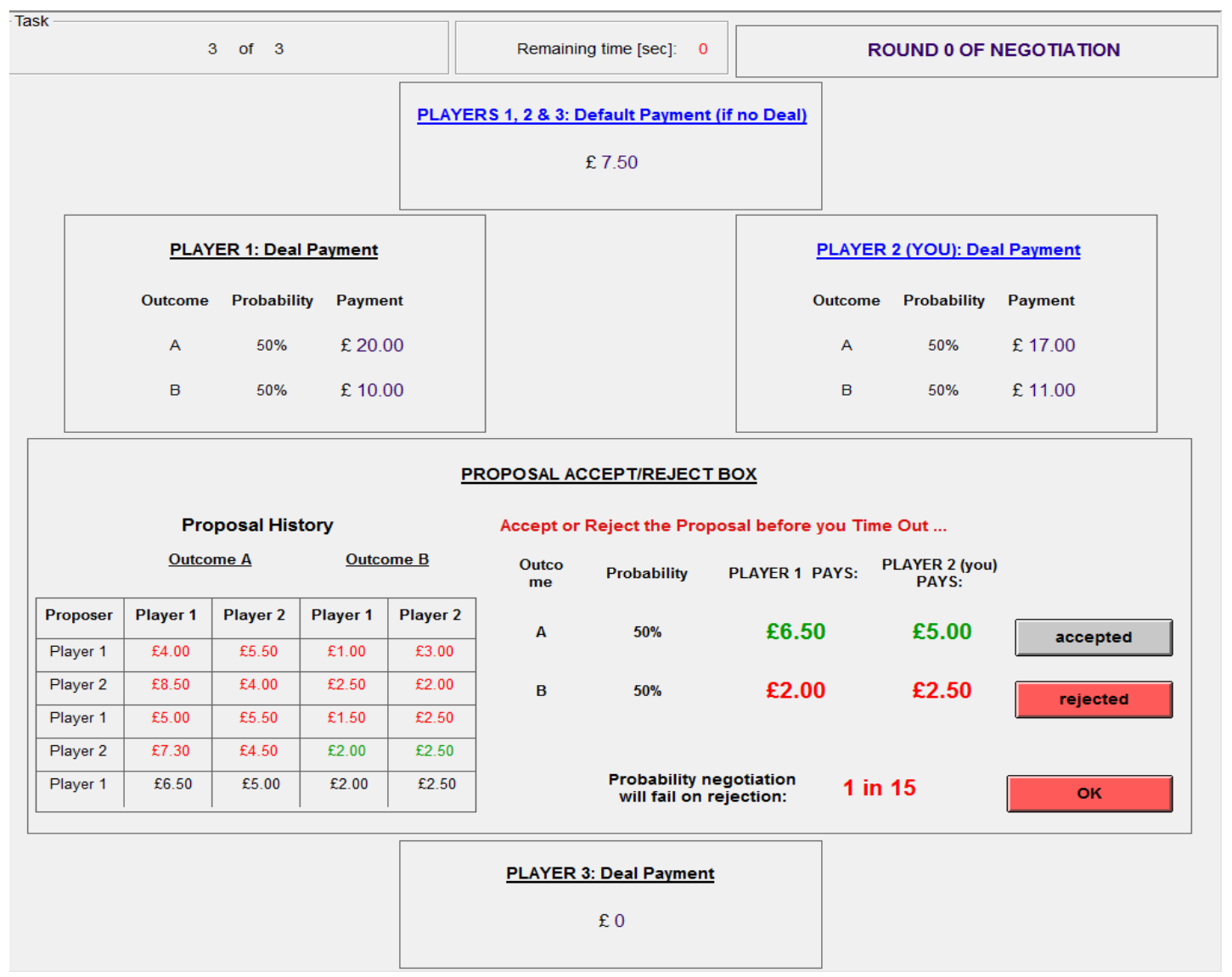

Screen: Offer Screen 
- Finally, when an Offer arrives with Player 3 they will see a screen like this, showing the payments that are being offered by Players 1 and 2 in the event of Outcome A and in the event of Outcome B.

- Player 3 can express their opinions on that Offer by toggling the decision buttons from "rejected" to "accepted". Try that now.

- Of course, Player 3 only avoids the risk associated with making a rejection if the payments proposed for both Outcomes are accepted. If that happens then all 3 Players have agreed and a DEAL is done.

- At the end of the experiment, if this task is the one that is chosen for real, then we need to find out whether Outcome A or Outcome B is the actual outcome. To do that we will simply toss a coin. If the coin comes up Heads then Outcome A is the actual outcome and you will get paid what you agreed to in the Deal under that outcome. Alternatively, if she coin comes up Tails then Outcome B is the actual outcome and you will get paid what you agreed to in the Deal under that outcome.

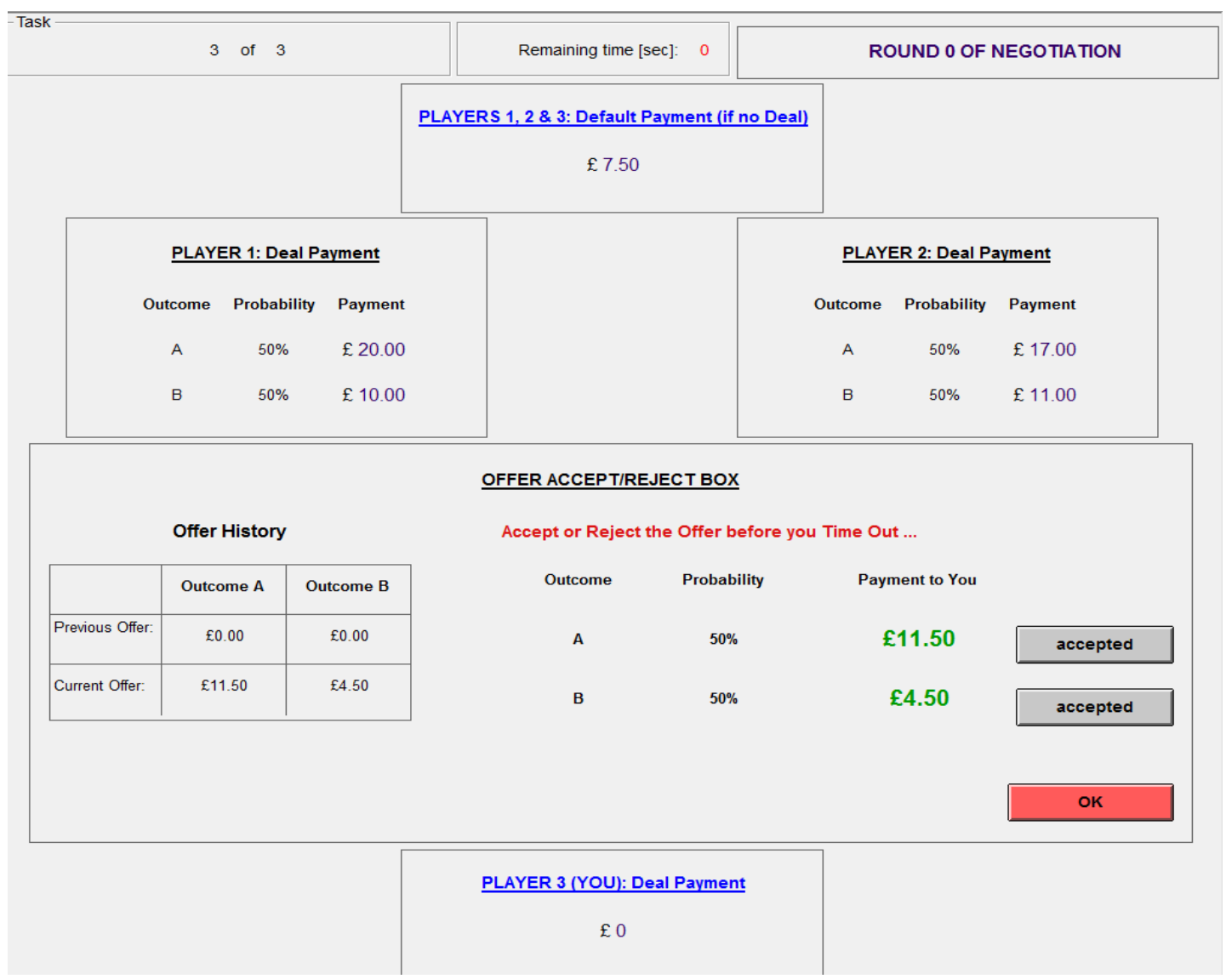




\section{Appendix B: Models of Non-Cooperative Multi-Purchaser PES Mechanisms}

We consider a stylised model in which two economic agents, Purchaser 1 and Purchaser 2, stand to benefit from the provision of ecosystem service flows. Purchaser 1 wishes to acquire more of service flow $a(S F a)$, while purchaser 2 wants more of service flow $b(S F b)$. We assume that both those service flows can be acquired by investing in a PES scheme that delivers a particular natural capital enhancement. We label this action, action $C$. Both purchasers can acquire the same service through some other method; $S F$ a through investing in action $A$ while $S F b$ through investing in action $B$. Note that these alternative methods of provision do not require the service flow to be delivered through natural capital enhancement. Our primary interest in examining this problem is to establish whether, and under what circumstances our two purchasers might be prepared to make investments in action $C$.

The key tension here is that action $C$ has public good properties. In buying action $C$, a purchaser not only benefits themselves through increasing the flow of the service flow from which they gain value but also benefits the other purchaser through increasing the other service flow as well. Accordingly, like any public goods problem, what we might expect to see is under-investment in action $C$ as a result of free-riding behaviour.

In order to simplify and to provide a clear focus on the purchaser side of the market, let us assume that each of the actions can be bought at some constant unit price. In particular, $£ 1$ of investment by a purchaser in action $A$ gives $x_{a}$ units of $S F a, £ 1$ of investment in Action $B$ gives $x_{b}$ units of $S F b$, while $£ 1$ of investment in action $C$ yields $\lambda_{a} x_{a}$ units of $S F a$ and $\lambda_{b} x_{b}$ units of $S F b$. Here $\lambda_{a}$ and $\lambda_{b}$ are non-negative scaling coefficients that tell us how much more or less of each service flow is provided by investing in Action $C$ as compared to the other possible outcomes. For example, if $\lambda_{a}>1$ then for the same investment, a purchaser gets more of $S F$ a by buying Action $C$ than from buying Action $A$; in such a case we would 
say that Action $C$ is more cost-efficient than Action $A$. Indeed, different values for $\lambda_{a}$ and $\lambda_{b}$, define a number of possible cases;

\begin{tabular}{|c|c|c|}
\hline Case 1 & $\lambda_{\mathrm{a}}>1$ and $\lambda_{\mathrm{b}}>1$ & $C$ is more cost efficient than $A$ and $B$ \\
\hline \multirow{3}{*}{ Case 2} & $\lambda_{\mathrm{a}}>1$ and $\lambda_{\mathrm{b}}<1$ & $C$ is more cost efficient than $A$ but not $B$ \\
\hline & Or & Or \\
\hline & $\lambda_{a}<1$ and $\lambda_{b}>1$ & $C$ is more cost efficient than $B$ but not $A$ \\
\hline Case 3 & $\begin{array}{c}\lambda_{a}<1 \text { and } \lambda_{b}<1 \\
\text { and } \\
\lambda_{a}+\lambda_{b}>1\end{array}$ & $\begin{array}{c}C \text { is more cost efficient than a mix of } A \\
\text { and } B\end{array}$ \\
\hline Case 4 & $\begin{array}{c}\lambda_{a}<1 \text { and } \lambda_{b}<1 \\
\text { and } \\
\lambda_{a}+\lambda_{b} \leq 1\end{array}$ & $\begin{array}{l}C \text { is less cost efficient than a mix of } A \text { and } \\
\qquad B\end{array}$ \\
\hline
\end{tabular}

The parameters $\lambda_{a}$ and $\lambda_{b}$ are crucial for this analysis since they determine the relative merits of investing in action $C$; in other words, participating in the PES mechanism. So if, for example, $\lambda_{a}>1$, then action $C$ always gives a better return per $£$ than action $A$. In that case, Purchaser 1 would only ever invest in action $C$. Likewise, if the opposite is true and $\lambda_{a}<1$, then Purchaser 1 will have strong incentives only to purchase quantities of action $A$. A similar argument holds for $\lambda_{b}$ and Purchaser 2's decisions as to whether to invest in action $C$ or $B$.

With our simplified model in place, we can now explore the obstacles and opportunities for developing a PES mechanism designed to facilitate purchasers making investments in Action $C$. To do that, we posit a payoff function for each purchaser which is increasing (at a declining rate) in the levels of service flow and use methods of non-cooperative game theory to explore how the purchasers will behave under different market set-ups and in response to different mechanisms and interventions.

Assume that the two purchasers have the following quadratic payoff functions; 


$$
\begin{array}{ll}
\text { Purchaser 1: } & \Pi_{1}=a_{0} X_{a}-\frac{1}{2} a_{1} X_{a}{ }^{2}-C_{1} \\
\text { Purchaser 2: } & \Pi_{2}=b_{0} X_{b}-\frac{1}{2} b_{1} X_{b}{ }^{2}-C_{2}
\end{array}
$$

where, $X_{a}$ is the quantity of service flow $a$ enjoyed by Purchaser 1 and $X_{b}$ the quantity of service flow $b$ enjoyed by Purchaser $2, C_{1}$ and $C_{2}$ are costs incurred by Purchaser 1 and 2 respectively and $a_{0}, a_{1}, b_{0}$ and $b_{1}$ are parameters of the two payoff functions.

Now imagine a PES market institution which allows Purchasers to purchase quantities of actions $\mathrm{A}, \mathrm{B}$ or $\mathrm{C}$. In this case, the payoffs functions are;

Purchaser $1: \Pi_{1}=a_{0}\left(R_{1}^{A} x_{a}+\left(R_{1}^{C}+R_{2}^{C}\right) \lambda_{a} x_{a}\right)-\frac{1}{2} a_{1}\left(R_{1}^{A} x_{a}+\left(R_{1}^{C}+R_{2}^{C}\right) \lambda_{a} x_{a}\right)^{2}-$ $\left(R_{1}^{A}+R_{1}^{C}\right)$

Purchaser 2: $\Pi_{2}=b_{0}\left(R_{2}^{B} x_{b}+\left(R_{1}^{C}+R_{2}^{C}\right) \lambda_{b} x_{b}\right)-\frac{1}{2} b_{1}\left(R_{2}^{B} x_{b}+\left(R_{1}^{C}+R_{2}^{C}\right) \lambda_{b} x_{b}\right)^{2}-$ $\left(R_{2}^{A}+R_{2}^{A}\right)$

where $R_{i}^{A}, R_{i}^{B}$ and $R_{i}^{C}(i \in 1,2)$ are the amounts that Purchaser $i$ spends on actions $A, B$ and $C$ respectively. We simplify by imposing $R_{1}^{B}=0$ and $R_{2}^{A}=0$ under the assumption that rational Purchasers will not invest in an action that returns none of the ES service that they value.

The optimal choice of $R_{1}^{A}$ and $R_{1}^{C}$ for Purchaser 1 can be found by forming the Lagrange:

$$
\begin{aligned}
L_{1}=a_{0} x_{a}\left(R_{1}^{A}\right. & \left.+\lambda_{a}\left(R_{1}^{C}+R_{2}^{C}\right)\right)-\frac{1}{2} a_{1} x_{a}{ }^{2}\left(R_{1}^{A}+\lambda_{a}\left(R_{1}^{C}+R_{2}^{C}\right)\right)^{2}-\left(R_{1}^{A}+R_{1}^{C}\right)+\gamma_{1}^{A} R_{1}^{A} \\
& +\gamma_{1}^{C} R_{1}^{C}
\end{aligned}
$$

where $\gamma_{1}^{A}$ and $\gamma_{1}^{C}$ are the Lagrange multipliers on the non-negativity constraints on $R_{1}^{A}$ and $R_{1}^{C}$ respectively and arrive at the gradient conditions;

$$
\frac{\partial \Pi_{1}}{\partial R_{1}^{A}}=a_{0} x_{a}-a_{1} x_{a}^{2}\left(R_{1}^{A}+\lambda_{a}\left(R_{1}^{C}+R_{2}^{C}\right)\right)=1-\gamma_{1}^{A}
$$




$$
\frac{\partial \Pi_{1}}{\partial R_{1}^{C}}=\lambda_{a}\left\{a_{0} x_{a}-a_{1} x_{a}{ }^{2}\left(R_{1}^{A}+\lambda_{a}\left(R_{1}^{C}+R_{2}^{C}\right)\right)\right\}=1-\gamma_{1}^{C}
$$

Complementary slackness conditions;

$$
\begin{aligned}
& \gamma_{1}^{A} R_{1}^{A}=0 \\
& \gamma_{1}^{C} R_{1}^{C}=0
\end{aligned}
$$

Primal constraint conditions;

$$
\begin{aligned}
& R_{1}^{A} \geq 0 \\
& R_{1}^{C} \geq 0
\end{aligned}
$$

And dual constraint conditions;

$$
\begin{aligned}
& \gamma_{1}^{A} \geq 0 \\
& \gamma_{1}^{C} \geq 0
\end{aligned}
$$

Dividing (2) by (1) gives;

$$
\lambda_{a}=\frac{1-\gamma_{1}^{C}}{1-\gamma_{1}^{A}}
$$

It follows that if $\lambda_{a}>1$, then $1-\gamma_{1}^{C}>1-\gamma_{1}^{A}$ which implies $\gamma_{1}^{A}>\gamma_{1}^{C}$. Given the dual constraint conditions, (7) and (8), the condition $\gamma_{1}^{A}>\gamma_{1}^{C}$ can only hold if;

- $\quad \gamma_{1}^{A}>0$ and $\gamma_{1}^{C}>0$; which from (3) and (4) means $R_{1}^{A}=R_{1}^{C}=0$ and Purchaser 1 buys no actions.

- $\gamma_{1}^{A}>0$ and $\gamma_{1}^{C}=0$; which from (3) and (4) means $R_{1}^{A}=0$ and $R_{1}^{C}>0$, such that Purchaser 1 only buys quantities of action $C$.

The intuition is clear, if $\lambda_{a}>1$ then action $C$ always gives a better return per $£$ than action $A$, so Purchaser 1 will only ever invest in action $C$. In the contrary case when $\lambda_{a}<1$, it follows from (9) that $\gamma_{1}^{A}<\gamma_{1}^{C}$ such that Purchaser 1 will only ever buy quantities of action $A$ (if he 
buys any actions at all). The same principles hold for the analysis of the problem from the point of view of Purchaser 2. So our first result is the obvious conclusion that any Purchaser who finds Action $\mathrm{C}$ more cost efficient than alternative actions will only ever invest in $\mathrm{C}$. Likewise a Purchaser will never invest in Action C if it is less cost efficient than some alternative.

\section{CASE 1: $\lambda_{a}>1$ and $\lambda_{b}>1$}

In this case, Action $\mathrm{C}$ is more cost efficient than the alternative for both Purchasers.

Accordingly, $R_{1}^{A}=R_{2}^{B}=0$ and $\gamma_{1}^{C}=\gamma_{2}^{C}=0$ such that (1) or (2) reduce to;

$$
\lambda_{a}\left\{a_{0} x_{a}-a_{1} x_{a}^{2}\left(R_{1}^{C}+R_{2}^{C}\right) \lambda_{a}\right\}=1
$$

From which we solve for the response curve;

$$
R_{1}^{C}=\frac{\lambda_{a} a_{0} x_{a}-1}{a_{1} x_{a}{ }^{2} \lambda_{a}{ }^{2}}-R_{2}^{C}
$$

Similarly for Purchaser 2 we get;

$$
\lambda_{b}\left\{b_{0} x_{b}-b_{1} x_{b}^{2}\left(R_{1}^{C}+R_{2}^{C}\right) \lambda_{b}\right\}=1
$$

With response curve;

$$
R_{2}^{C}=\frac{\lambda_{b} b_{0} x_{b}-1}{b_{1} x_{b}^{2} \lambda_{b}^{2}}-R_{1}^{C}
$$

So in the case where action $\mathrm{C}$ is more cost efficient than both $\mathrm{A}$ and $\mathrm{B}$, we have parallel response curves. This game results in a Nash Equilibrium in which either Purchaser 1 or 2 (depending on the relative sizes of the parameters) completely free-ride on the other's purchases of $C$. 
The intuition here is straightforward. Imagine Purchaser 2 gets more value from units of action $C$ than Purchaser 1. Imagine too that Purchaser 1 starts out ignoring what Purchaser 2 is going to do and buys as much of action $C$ as would make sense for them to do if they were the only purchaser. Of course, Purchaser 2 benefits greatly from the units of action $C$ that have been bought by Purchaser 1 . Now, since Purchaser 2 values action $C$ more highly than Purchaser 1, their optimal response would be to also invest some of their own money and buy some additional units of action $C$. Since Purchaser 2 is now buying some action $C$, however, it no longer makes sense for Purchaser 1 to buy as much as they had planned to originally. Accordingly, we would expect Purchaser 1 to decide to buy less of action $C$. Unfortunately, for Purchaser 2 that means that they are not gaining as much as previously from Purchaser 1's funding of action $C$. Their best response is to buy yet more of action $C$, which again encourages Purchaser 1 to reduce their contribution. That sequence of events would continue until Purchaser 1 is buying no units of action $C$, but simply free-riding on the units funded by Purchaser 2.

Our first conclusion then is that in a simple market structure, even when action $C$ is cost efficient for both players it is likely that only one purchaser will end up paying for action $C$.

\section{CASE 2: $\lambda_{a}>1$ and $\lambda_{b}<1$}

In this case Action $\mathrm{C}$ is more cost efficient than alternative actions for one of the Purchasers (by way of illustration we choose that Purchaser to be Purchaser 1), but less cost efficient for the other.

- For Purchaser 1: Since $\lambda_{a}>1$, we have from (9) that $\gamma_{1}^{A}>0$ and $\gamma_{1}^{C}=0$ implying $R_{1}^{A}=$ 0 and $R_{1}^{C}>0$. Purchaser 1 will only invest in action $\mathrm{C}$.

- For Purchaser 2: Since $\lambda_{b}<1$, the equivalent relationship gives $\gamma_{2}^{B}=0$ and $\gamma_{2}^{C}>0$ implying $R_{2}^{B}>0$ and $R_{2}^{C}=0$. Purchaser 2 will only invest in action B. 
Using those values, we solve for the response curves;

Purchaser 1: $\quad R_{1}^{C}=\frac{\lambda_{a} a_{0} x_{a}-1}{a_{1} x_{a}{ }^{2} \lambda_{a}{ }^{2}}$

Purchaser 2:

$$
R_{2}^{B}=\frac{b_{0} x_{b}-1}{b_{1} x_{b}^{2}}-\lambda_{b} R_{1}^{C}
$$

So in this case Purchaser 1 buys their optimal quantity of action $C$ and this is independent of Purchaser 2's actions. In contrast, Purchaser 2 only buys action $B$, but only when Purchaser 1's purchases of action $C$ result in less than $\left(b_{0} x_{b}-1\right) / b_{1} x_{b}{ }^{2}$ of SF $b$ being provided. Again the conclusion is that only one player will have incentives to invest in action $C$.

\section{CASE $3 \&$ 4: $\lambda_{a}<1$ and $\lambda_{b}<1$}

In the final case, Action $\mathrm{C}$ is less cost efficient than either $\mathrm{A}$ or $\mathrm{B}$. So $R_{1}^{C}=R_{2}^{C}=0$ and $\gamma_{1}^{A}=$ $\gamma_{2}^{B}=0$ and the optimum for Purchaser 1 is to buy only action A;

$$
R_{1}^{A}=\frac{a_{0} x_{a}-1}{a_{1} x_{a}^{2}}
$$

And for Purchaser 2 to buy only action B;

$$
R_{2}^{B}=\frac{b_{0} x_{b}-1}{b_{1} x_{b}^{2}}
$$

In this final case, Action $C$ is less cost efficient than either A or B. Accordingly the optimal plan for Purchaser 1 is to buy only action $A$ and for Purchaser 2 to buy only action $B$. No units of action $C$ are bought.

Our analysis reveals a very important insight; without further structure to the market mechanism, the public good nature of actions delivering ecosystems services are likely to lead to only one purchaser investing in those actions. That purchaser will be the purchaser that gains the most value from those actions. Other purchasers will simply free-ride. 


\section{References}

Asquith, N.M., Vargas, M.T., Wunder, S., 2008. Selling two environmental services: In-kind payments for bird habitat and watershed protection in Los Negros, Bolivia. Ecol Econ $65,675-684$.

Ausubel, L.M., Cramton, P., Deneckere, R., 2002. Bargaining with Incomplete Information, in: Aumann, R.J., Hart, S. (Eds.), Handbook of Game Theory: Vol. 3. Elsevier, Amsterdam, pp. 1897-1945.

Banerjee, S., de Vries, F.P., Hanley, N., van Soest, D.P., 2014. The Impact of Information Provision on Agglomeration Bonus Performance: An Experimental Study on Local Networks. Am J Agr Econ 96, 1009-1029.

Banerjee, S., Kwasnica, A.M., Shortle, J.S., 2012. Agglomeration bonus in small and large local networks: A laboratory examination of spatial coordination. Ecol Econ 84, 142152.

Barnett, B.J., 2000. The US Federal Crop Insurance Program. Can J Agr Econ 48, 539-551.

Barrett, S., 1994. Self-Enforcing International Environmental Agreements. Oxford Econ Pap 46, 878-894.

Berger, L.A., Hershey, J.C., 1994. Moral Hazard, Risk Seeking, and Free Riding. Journal of Risk and Uncertainty 9, 173-186.

Blackman, A., Woodward, R.T., 2010. User financing in a national payments for environmental services program: Costa Rican hydropower. Ecol Econ 69, 1626-1638.

Bolton, G., Ockenfels, A., 2000. ERC: A Theory of Equity, Reciprocity, and Competition. Am Econ Rev 90, 166-193.

Bruce, C., Clark, J., 2010a. The Effect of Entitlements and Equality on Cooperative Bargaining with Private, Unverifiable Information. Working Papers in Economics 10/68, University of Canterbury, Department of Economics and Finance.

Bruce, C., Clark, J., 2010b. The Efficiency of Direct Public Involvement in Environmental Policymaking: An Experimental Test. Environmental and Resource Economics 45, 157 182.

Bruce, C., Clark, J., 2012. The impact of entitlements and equity on cooperative bargaining: an experiment. Economic Inquiry 50, 867-879.

Cadigan, J., Schmitt, P.M., Shupp, R., Swope, K., 2009. An Experimental Study of the Holdout Problem in a Multilateral Bargaining Game. Southern Economic Journal 76, 444-457.

Camerer, C., 2003. Behavioral Game Theory, Experiments in Strategic Interaction. Princeton University Press, New Jersey, USA.

Carnevale, P.J., Pruitt, D.G., 1992. Negotiation and Mediation. Annu Rev Psychol 43, 531582.

Coase, R.H., 1960. The Problem of Social Cost. J Law Econ 3, 1-44.

Croson, R., Boles, T., Murnighan, J.K., 2003. Cheap talk in bargaining experiments: lying and threats in ultimatum games. Journal of Economic Behavior I\& Organization 51, 143 -159 . 
Day, B., Couldrick, L., 2013. Payment for Ecosystem Services Pilot Project: The Fowey River Improvement Auction. Defra, London.

Deal, R.L., Cochran, B., LaRocco, G., 2012. Bundling of ecosystem services to increase forestland value and enhance sustainable forest management. Forest Policy Econ 17, 6976.

Defra, 2013. Developing the potential for Payments for Ecosystem Services: an Action Plan. Department for Environment, Food and Rural Affairs, London, UK.

Dickinson, D.L., 1998. The voluntary contributions mechanism with uncertain group payoffs. Journal of Economic Behavior \& Organization 35, 517-533.

Fauzi, A., Anna, Z., 2013. The complexity of the institution of payment for environmental services: A case study of two Indonesian PES schemes. Ecosystem Services 6, 54-63.

Feiock, R.C., 2013. The Institutional Collective Action Framework. Policy Stud J 41, 397 425.

Fischbacher, U., 2007. z-Tree: Zurich toolbox for ready-made economic experiments. Experimental Economics 10, 171-178.

Gomez-Baggethun, E., de Groot, R., Lomas, P.L., Montes, C., 2010. The history of ecosystem services in economic theory and practice: From early notions to markets and payment schemes. Ecol Econ 69, 1209-1218.

Greiner, B., 2004. The Online Recruitment System ORSEE 2.0 - A Guide for the Organization of Experiments in Economics, Working Paper Series in Economics, University of Cologne, Department of Economics.

Guth, W., Huck, S., Ockenfels, P., 1996. Two-Level Ultimatum Bargaining with Incomplete Information: An Experimental Study. Economic Journal 106, 593--604.

Hoffman, E., Spitzer, M.L., 1985. Entitlements, Rights, and Fairness: An Experimental Examination of Subjects' Concepts of Distributive Justice. Journal of Legal Studies 14, 259-297.

Kennan, J., Wilson, R., 1993. Bargaining with Private Information. Journal of Economic Literature 31, 45-104.

Keser, C., Montmarquette, C., 2008. Voluntary contributions to reduce expected public losses. Journal of Economic Behavior \& Organization 66, 477-491.

Koremenos, B., Lipson, C., Snidal, D., 2001. The rational design of international institutions. Int Organ 55, 761-+.

Krawczyk, M., Bartczak, A., Hanley, N., Stenger, A., 2016. Buying spatially-coordinated ecosystem services: An experiment on the role of auction format and communication. Ecol Econ 124, 36-48.

Laffont, J.-J., Tirole, J., 1993. A theory of incentives in procurement and regulation. MIT press.

LaRocco, G., Deal, R.L., 2011. Giving credit where credit is due: increasing landowner compensation for ecosystem services. Gen. Tech. Rep. PNW-GTR-842. Portland, OR: U.S. Department of Agriculture, Forest Service, Pacific Northwest Research Station.

Murnighan, J.K., Babcock, L., Thompson, L., Pillutla, M., 1999. The information dilemma in negotiations: Effects of experience, incentives, and integrative potential. Int J Confl Manage 10, 313-339. 
Muthoo, A., 2002. The Economics of Bargaining, Knowledge for Sustainable Development: An Insight into the Encyclopedia of Life Support Systems. EOLSS Publishers/UNESCO.

Nordhaus, W., 2015. Climate Clubs: Overcoming Free-riding in International Climate Policy. Am Econ Rev 105, 1339-1370.

Osborne, M., Rubinstein, A., 1994. A Course in Game Theory. The MIT Press, London, UK.

Ostrom, E., 2012. The Future of the Commons: Beyond Market Failure and Government Regulation. Institute of Economic Affairs, London.

Parkhurst, G.M., Shogren, J.F., 2007. Spatial incentives to coordinate contiguous habitat. Ecol Econ 64, 344-355.

Perrot-Maitre, D., 2006. The Vittel payments for ecosystem services: a "perfect” PES case? International Institute for Environment and Development, London, UK.

Pillutla, M.M., Murnighan, J.K., 1996. Unfairness, Anger, and Spite: Emotional Rejections of Ultimatum Offers. Organ Behav Hum Dec 68, 208-224.

Rapoport, A., Sundali, J.A., Seale, D.A., 1996. Ultimatums in two-person bargaining with one-sided uncertainty: Demand games. Journal of Economic Behavior $\backslash \&$ Organization 30, 173--196.

Raudsepp-Hearne, C., Peterson, G.D., Bennett, E.M., 2010. Ecosystem service bundles for analyzing tradeoffs in diverse landscapes. P Natl Acad Sci USA 107, 5242-5247.

Reeson, A.F., Rodriguez, L.C., Whitten, S.M., Williams, K., Nolles, K., Windle, J., Rolfe, J., 2011. Adapting auctions for the provision of ecosystem services at the landscape scale. Ecol Econ 70, 1621-1627.

Roth, A.E., 1995. Bargaining Experiments, in: Kagel, J.H., Roth, A.E. (Eds.), The Handbook of Experimental Economics. Princeton University Press, New Jersey, pp. 253-348.

Roth, A.E., Malouf, M.W.K., 1979. Game-theoretic models and the role of information in bargaining. Psychological Review 86, 574-594.

Roth, A.E., Malouf, M.W.K., Murnighan, J.K., 1981. Sociological versus strategic factors in bargaining. Journal of Economic Behavior \& Organization 2, 153-177.

Roth, A.E., Murnighan, J.K., 1982. The Role of Information in Bargaining: An Experimental Study. Econometrica 50, 1123-1142.

Sattler, C., Trampnau, S., Schomers, S., Meyer, C., Matzdorf, B., 2013. Multi-classification of payments for ecosystem services: How do classification characteristics relate to overall PES success? Ecosystem Services 6, 31-45.

Schmitt, P.M., 2004. On Perceptions of Fairness: The Role of Valuations, Outside Options, and Information in Ultimatum Bargaining Games. Experimental Economics 7, 49--73.

Schomers, S., Matzdorf, B., 2013. Payments for ecosystem services: A review and comparison of developing and industrialized countries. Ecosystem Services 6, 16-30.

Shavell, S., 1979. Risk Sharing and Incentives in the Principal and Agent Relationship. Bell J Econ 10, 55-73.

Shupp, R., Cadigan, J., Schmitt, P.M., Swope, K.J., 2013. Institutions and information in multilateral bargaining experiments. The B.E. Journal of Economic Analysis \& Policy $13,485-524$. 
Smith, G., Day, B., 2014. When Should We Use Multiple-Purchaser Payments For Ecosystem Services Schemes?, 16th Annual BIOECON Conference, Cambridge, UK.

Smith, L.E.D., Porter, K.S., 2010. Management of catchments for the protection of water resources: drawing on the New York City watershed experience. Reg Environ Change $10,311-326$.

Stoneham, G., Chaudhri, V., Ha, A., Strappazzon, L., 2003. Auctions for conservation contracts: an empirical examination of Victoria's BushTender trial. Australian Journal of Agricultural and Resource Economics 47, 477-500.

Sutton, J., 1986. Non-cooperative Bargaining Theory: An Introduction. Review of Economic Studies 53, 709-724.

Thompson, L., Hastie, R., 1990. Social-Perception in Negotiation. Organ Behav Hum Dec 47, 98-123.

Varian, H.R., 1994. A Solution to the Problem of Externalities When Agents Are WellInformed. Am Econ Rev 84, 1278-1293.

Zwick, R., Chen, X.-P., 1999. What Price Fairness? A Bargaining Study. Management Science 45, 804-823.

Zwick, R., Mak, V., 2012. Gaming with Fairness: Some Conjectures on Behavior in Alternating Offer Bargaining Experiments, in: Bolton, G., Croson, R. (Eds.), The Oxford Handbook of Economic Conflict Resolution. Oxford University Press. 